\title{
The Impact of Industrial Odors on the Subjective Well-Being of Communities in Colorado
}

\author{
Mohamed A. Eltarkawe and Shelly L. Miller * (D) \\ Mechanical Engineering Department, University of Colorado Boulder, Sustainability, Energy and Environment \\ Complex, East Campus, 4001 Discovery Drive, Boulder, CO 80303, USA; Mohamed.eltarkawe@colorado.edu \\ * Correspondence: shelly.miller@colorado.edu; Tel.: +1-303-492-0587
}

Received: 26 April 2018; Accepted: 23 May 2018; Published: 28 May 2018

\begin{abstract}
Odor pollution was identified as a top priority of the community of North Denver. Previous studies that investigated the impact of air pollution in North Denver focused on adverse health effects, rather than mental well-being. This study assessed the impact of odors from industrial sources on the subjective well-being (SWB) of North Denver residents, and of four similar communities in Colorado for comparison. An online survey was sent to participants from Greeley, Fort Collins, Fort Lupton, North Denver, and Pueblo, asking questions about SWB and odors in their areas $(n=351)$. The evaluation of SWB was performed using a novel approach that appraises three aspects of SWB. This approach of evaluating SWB has not been used in odor exposure studies. A proportional odds logistic regression model was used to estimate nine measures of SWB. The results showed that participants who reported that the air is very fresh or the odor is highly acceptable had higher levels of SWB. This association suggests that residents who live in areas exposed to strong industrial odors had lower levels of SWB. A subset of participants in this study took the survey four times in one year. Longitudinal analysis showed that evaluative satisfaction was slightly associated with seasonality. Both satisfaction with how life turned out and satisfaction with standards of living slightly increased during the fourth quarter of the year. The study also found that four of the nine measures can be used to represent SWB in future studies. Two of those measures were evaluative SWB, and the other two were positive hedonic SWB measures. A comparison between the five communities showed that well-being levels in North Denver and Greeley were not significantly different than those in Fort Collins or Fort Lupton. The comparison, however, showed that Pueblo had the lowest levels of well-being among all communities.
\end{abstract}

Keywords: evaluative well-being; air quality; Globeville; Elyria Swansea; hedonic well-being

\section{Introduction}

The residents of the northern part of the Denver metropolitan area frequently experience odors from commercial and industrial businesses, two major highways, railyards, and utilities. Globeville and Elyria Swansea are probably the most affected neighborhoods in North Denver, in which over $70 \%$ of their areas contain these types of businesses. The residents of both neighborhoods, who are predominantly Hispanic (Globeville is $68 \%$ and Elyria Swansea $84 \%$ Hispanic) have a long history of odor complaints. Since 2004, Denver City has received 1322 odor complaints [1]. According to the 2014 Globeville and Elyria Swansea Health Impact Assessment Report [2], odor pollution was identified as a top priority of the community of Globeville and Elyria Swansea. One example of the odors experienced in Globeville is an intermittent and unpredictable coal tar odor that can cause burning eyes and throat, headaches, skin irritation, and sleep problems. In response to odor complaints and concerns in North Denver, a University of Colorado Boulder study, funded by an environmental justice grant from the U.S. Environmental Protection Agency (EPA), was conducted with the Globeville community 
in 2012. The aim was to address the odor issue by attempting to identify pollutants responsible for the coal tar odor and to link the odor with pollutants emitted from specific facilities [3]. The EPA study concluded that coal tar odors were frequently reported and high levels of naphthalene were measured when the winds came from the Northwest, bringing emissions from the creosote facility, Koppers Inc., into the community. However, all pollutant concentrations were below the odor and toxicity thresholds. The study recommended a more detailed investigation to explain the effects of all industrial odors in Globeville and the surrounding communities, and to assess the relationship between odor exposure and well-being.

Understanding the psychological impact (impact on quality of life) of odor exposure, in particular odors from industrial sources, in the nearby residential communities is challenging [4,5]. Assessment of this relationship is difficult because both the exposure and response are hard to measure and there is no universal technique that could be applied to evaluate them. Odors are a complex mixture of chemicals and most of them have potential odorous impacts at very low concentrations [6]. The strength of odors in ambient air is associated with the concentrations of the chemical components, mainly volatile organic compounds (VOCs) [7]. Studies show that odors cause nuisance and acute health effects such as headaches, nausea, and eye and throat irritation [8]. Exposure to intensive odors increased inflammation in the nose and respiratory area [9], and caused a histamine release [10]. In some cases, odors can even cause death due to toxic compounds [11].

Odors are characterized with instrumental or odor sensory methods. The instrumental methods measure the chemical components of odors in the air, typically using gas chromatography/mass spectrometry [12] or photoionization detectors [13]. The sensory method (sometimes called perceived air quality) involves a human panel to assess air quality and/or odor exposure. Odor sensory methods are often more helpful than instrumental methods in many applications, because they do not have a limit of detection issue and reflect the actual human perception of odor. Bereznicki et al. [14] compared perceived odors and chemical emissions from dairy and swine facilities and found the two methods were comparable. Many studies preferred perceived air quality assessment in indoor environments [15-21]. It has also been used in outdoor applications [6,22,23].

Using standardized questionnaires for odor exposure assessment is common and reliable. A six-point scale question about odor intensity (odor strength from $1=$ very slight to $6=$ extremely strong) and a nine-point scale question about hedonic tone (pleasant and unpleasant odor), in addition to odor frequency data, were used in an odor exposure assessment study [24]. In a study about the association between environmental odor exposure from a fertilizer plant for mushroom cultivation and somatic symptoms [25], a standardized survey was used to evaluate the degree of odor annoyance (eleven-point scale). Luginaah [26] used community health surveys to evaluate the changes in odor perception and odor annoyance between 1992 and 1997. Anonymous questionnaires were used to evaluate the degree of perceived annoyance in a study that investigated the relationship between outdoor air pollution from livestock facilities and perceived odor annoyance [4]. The degree of annoyance was assessed by a five-point scale question, ranging from 0 (not annoying) to 4 (extremely annoying). Pedersen [27] used a five-point scale from 1 (do not notice) to 5 (very annoyed) to assess odor exposure.

Both academic and policy circles have showed an increased interest in the impact of quality of life recently, which is a catch-all term used to describe the health, comfort, and happiness experienced by an individual. Many aspects need to be addressed when measuring quality of life (e.g., economic, subjective, objective, and environmental components). Subjective well-being (SWB) is one of the most frequent methods used to measure quality of life, which is often done using surveys. Well-being is defined most simply as the state of being comfortable, healthy, or happy.

Satisfaction and happiness are widely used to measure subjective well-being [27-33]. However, recent studies required a distinction between two important aspects when subjective well-being is evaluated [34-38]. The first aspect is evaluative well-being, EWB (sometimes called global well-being or life evaluation), which can be measured by the overall judgment of life, such as general life 
satisfaction and general happiness. The second aspect is hedonic well-being, HWB (feelings and mood), which can be measured by experienced happiness, enjoyment, stress, or sadness. In addition, hedonic well-being is often divided into positive hedonic well-being $(+\mathrm{HWB})$ and negative hedonic well-being $(-\mathrm{HWB})[36,37]$. According to Hicks et al. [37], when subjective well-being data are collected, these three aspects of well-being $(\mathrm{EWB},+\mathrm{HWB}$, and $-\mathrm{HWB})$ should be reflected.

All studies that have been conducted in the North Denver area mainly focused on linking air pollution or industrial odor pollution to odor sources or adverse health effects, not well-being [3,39]. There are, however, a few studies that investigated the impact of industrial odors on well-being in other locations. The focus of some of these studies was mainly on the impact of odor exposure on psychological stress. A study on the psychological impact of malodors from a mushroom fertilizer production plant found that levels of cortisol-a steroid hormone released in the human body in response to stress-are correlated with odorant exposure [40]. Luginaah et al. [26], in a study on the effects of odors from a petroleum refinery in Oakville, Ontario, found that the decrease in odor exposure led to a decrease in negative perception and concerns. Moreover, the same study found an association between psychological reaction to environmental stress and odor exposure. The association between stress and odor exposure was also confirmed in a cross-sectional study in animal research [41]. There is compelling evidence in the literature supporting that long-term psychological stress leads to diseases such as depression, and cardiovascular disease [42]. Recent research found a link between stress and human immunodeficiency virus (HIV) progression to acquired immunodeficiency syndrome (AIDS) [43].

Other studies focused on the impact of odor exposure (mainly from animal production) on mental state indices such as depression, anger, confusion, tension, fatigue, and ability to focus. Schiffman et al. [44] reported an association between unpleasant odors (from large hog operations) and mood state. The residents who were exposed to the strong swine odors were most likely to have higher levels of depression, anger, fatigue, confusion, and tension when compared with residents who were not exposed to such odors. This is supported by the findings of Nordin et al. [45], who found that unpleasant odors had a negative impact on ability to focus in a study on 55 young adults. In a field study, odor exposure from a pig production facility was correlated with increased annoyance and symptoms. The study also concluded that odor exposure could be a risk factor for lower well-being and adverse health [25].

This study investigates whether odors from industrial sources impair the subjective well-being (SWB) of residents in the often-low-income surrounding communities in Colorado. The study expands the scope and includes all north of Denver metropolitan neighborhoods (Sloan Lake, Wheat Ridge, West Highlands, Highlands, Chaffee Park, Sunny Side, Globeville, Elyria Swansea, Cole, Downtown, Northeast/North Park Hill, Montbello, Stapleton, E. Colfax, Aurora, and Commerce City). In addition, four other Colorado communities were chosen outside of Denver for comparison purposes. Three of them are demographically similar to Globeville and Elyria Swansea (disproportionately Hispanic, low household income, and low education). These three communities are Greeley, Fort Lupton, and Pueblo. Unlike these three communities, Fort Collins was selected to be different. Figure 1 shows the locations of the five communities, and Table 1 details some of the demographic information of the five communities [46-48]. This study closely investigates the impact of odor exposure on SWB using surveys. The evaluation of SWB is performed using the recent approach of the three aspects of subjective well-being $(\mathrm{EWB},+\mathrm{HWB}$, and $-\mathrm{HWB})$. Odor exposure, on the other hand, is evaluated using two odor-related variables; namely perceived odor and odor acceptability. To the best of our knowledge, this recent approach of evaluating SWB has not been used in odor exposure studies. 


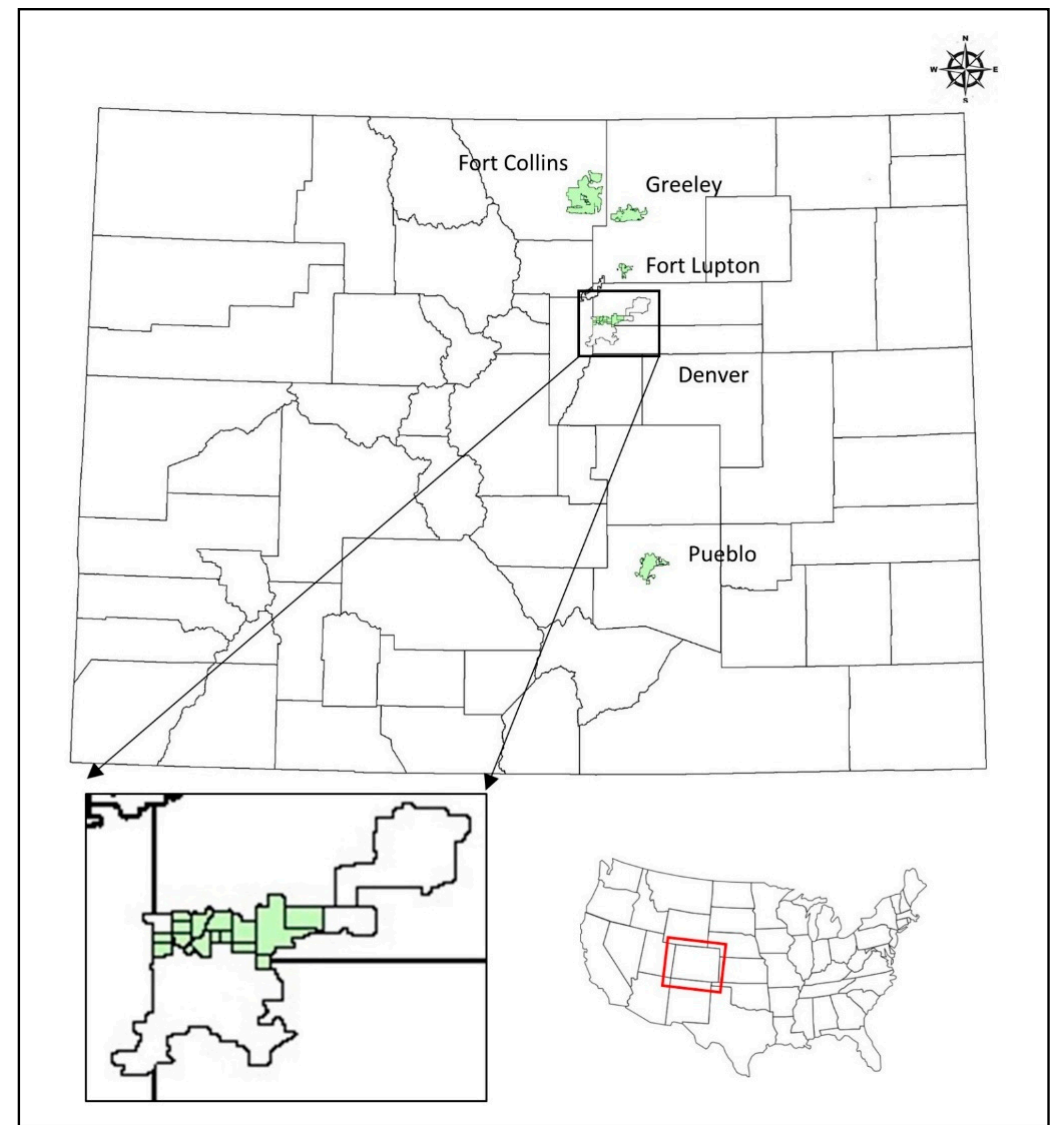

Figure 1. Locations of the five communities: Fort Collins in Larimer County, Greely and Fort Lupton in Weld County, North Denver in Denver County, and Pueblo in Pueblo County.

Table 1. Demographic information of the five communities.

\begin{tabular}{lccccc}
\hline \multicolumn{1}{c}{ Communities } & Population & $\begin{array}{c}\text { Median Household } \\
\text { Income (k) }\end{array}$ & $\begin{array}{c}\text { Average } \\
\text { Household Size }\end{array}$ & Hispanic (\%) & $\begin{array}{c}\text { Bachelor or } \\
\text { Higher (\%) }\end{array}$ \\
\hline Denver * & 600,158 & $\$ 50.3 \mathrm{k}$ & & 31.8 & 42.9 \\
$\quad$ Globeville & 3360 & $\$ 26.5 \mathrm{k}$ & 2.22 & 68.7 & 11.2 \\
Elyria Swansea & 6940 & $\$ 33.8 \mathrm{k}$ & & 81.8 & 11.3 \\
\hline Greeley City & 92,889 & $\$ 46.3 \mathrm{k}$ & 2.63 & 36.0 & 25.8 \\
\hline Fort Lupton City & 7377 & $\$ 50.2 \mathrm{k}$ & 3.09 & 55.0 & 8.9 \\
\hline Pueblo City & 106,595 & $\$ 34.7 \mathrm{k}$ & 2.37 & 49.8 & 19.7 \\
\hline Fort Collins City & 143,986 & $\$ 53.8 \mathrm{k}$ & 2.37 & 10.1 & 51.9 \\
\hline
\end{tabular}

* Denver data presented here are for the entire county of Denver, but the study focuses on the northern neighborhoods of Denver.

\section{Materials and Methods}

\subsection{Study Design}

A 60-question online survey was designed to collect data from the five Colorado communities. The online survey covers aspects related to SWB (48 questions), odors (5 questions), and demographic information (7 questions). The SWB part of the survey is a widely-used and validated survey that was adopted from the New Economics Foundation (NEF) in the United Kingdom (see the complete survey in Supplementary: Survey S1) [49].

The recruitment of study participants was done through contacts, flyer distribution, government entities, non-profit organizations, student clubs, and social media. Participation in the study was 
completely voluntary and participants could withdraw from it at any time without penalty or consequences. We recruited adult participants aged 18 or older, and all were required to consent before participating in the study. Any personal information was removed and the data were coded and kept confidential. Upon consent, the participants were given access to the online survey.

The last question in the online survey asked the participant to provide an email address to be contacted for further steps. The participants were asked to take the survey four times on a voluntary basis during the one-year study period (once every three months).

This study was approved by the University of Colorado Boulder's Institutional Review Board, Protocol \#16-0065.

\subsection{Variables of Interest}

The purpose of the online survey data collection was to quantify any relationships between SWB and the independent variables (demographics and odor-related characteristics). To measure SWB, three aspects of SWB were used: evaluative well-being (EWB), positive hedonic well-being $(+\mathrm{HWB})$, and negative hedonic well-being $(-\mathrm{HWB})[35,36,38]$. Each well-being aspect was measured by three questions from the online survey. EWB is a measure of general feeling, which includes the following: the participant is overall happy, the participant is satisfied with how life turned out, and the participant is satisfied with their standard of living. +HWB is a measure of recent positive feeling, which includes the following: the participant is satisfied with life nowadays, the participant enjoyed life last week, and the participant was happy last week. $-\mathrm{HWB}$ is a measure of recent negative feeling, which includes the following: the participant felt depressed last week, the participant could not get going last week (powerlessness), and the participant felt sad last week. The nine measures mentioned above were selected for this project based on the literature. They were selected to cover the three aspects of SWB used in many recent studies, with a focus on happiness and satisfaction [34-38]. All dependent variables were arranged from lower well-being to higher well-being scores. For example, recent happiness was arranged from none of the time I was recently happy to all the time I was recently happy. Similarly, recent depression was arranged from all the time I was depressed to none of the time I was depressed. In the results section, the selection of these nine measures is compared with a selection based on principal component analysis (PCA).

As explanatory (independent) variables, two odor-related variables of interest were chosen, as well as three demographic variables. The first odor-related variable is perceived odor, with response categories of air is very fresh, air is fresh, air is neutral, air has strong odor, and air has very strong odor. The second odor-related variable is odor acceptability, with response categories of low acceptability, middle acceptability, and high acceptability. Three binary demographic variables were considered as independent variables: employment (Yes, No), age (45-year-old or below, Above 45), and gender (Male, Female).

\subsection{Statistical Analysis}

\subsubsection{Principle Components Analysis}

Principal Component Analysis (PCA) is a widely-used data reduction procedure by which the matrix of possibly correlated variables is decomposed into eigenvectors. These eigenvectors will then be sorted based on the corresponding eigenvalues. Following the authors of [50], only eigenvectors with corresponding eigenvalues greater than or equal to one were considered. In the field of psychology, it is expected to have correlation between components. Therefore, it is more realistic to use the oblique rotation (oblimin) instead of orthogonal rotation (varimax). Data suitability procedures for factor analysis were carried out based on sample size and sample-to-variable ratios [51-53], Kaiser-Meyer-Olkin Test [54], Bartlett's Test [55], and correlation matrix (factorability) [56]. 


\subsubsection{Chi-Squared and Ordinal Logistic Regression}

The chi-squared test was used to explore relationships between the dependent variables (EWB, $+\mathrm{HWB}$, and $-\mathrm{HWB}$ measures) and the independent variables (employment, gender, age, perceived odor, and odor acceptability). An ordinal logistic regression model was also applied to quantify the associations between the variables.

An ordinal logistic regression is a model that can be used when the dependent variable is ordinal in nature, for example, the amount of time a person feels happy can be classified as all the time, most of the time, some of the time, and none of the time. The proportional odds regression was used in this study and it is one of the most popular and widely-used models among the ordinal regression models [57-59]. Confidence intervals of $95 \%$ were used to indicate whether significant association exists. The Lipsitz test was used to assess the goodness-of-fit for the ordinal logistic regression [57].

\subsubsection{Composite Scoring}

The Center of Well-being at NEF recommends using three sets of well-being questions. The first set is the Office for National Statistics (ONS) subjective well-being questions. This set of questions was added to the Integrated Household Survey (IHS) in April 2011. The IHS is a composite survey consisting of four questions that collects data from more than 200,000 people in United Kingdom (for ONS questions, see Table S1). The Short Warwick-Edinburgh Mental Well-being Scale (SWEMWBS) is the second set. It contains seven questions and each has five outcomes (see Table S2). These questions, designed by Warwick and Edinburgh University in 2006, are a validated and reliable measure of flourishing positive mental well-being (Health Survey for England, 2011). The third set contains a single question about social trust that is not a direct measure of $\mathrm{SWB}$, but it is a major driver of overall SWB-see Table S3 [49]. One advantage of NEF's well-being survey, which we used in our study, is that the survey contains all of the ONS questions, five questions of SWEMWBS, and the social trust question. Two questions from the SWEMWBS set are not available in NEF's survey (ability to think clearly and to make up your mind about things). Both questions were ignored when we calculated the composite score of SWEMWBS. Social trust measure was excluded as it is not a direct measure of SWB.

Another advantage of NEF's SWB survey is that the survey questions can be divided into SWB explanatory groups and SWB measures. The SWB explanatory groups include: social (four questions), employment (seven questions), health (three questions), appreciation (five questions), and freewill (two questions). In addition to these groups from NEF, our survey includes an odor-related group (four questions) and demographics (seven questions), which were added to the survey as a part of the study design.

\section{Results and Discussion}

\subsection{Sample Size}

Four different approaches were compared to determine the sample size in our study. First, a power analysis for an ordinal logistic regression was conducted to determine a sufficient sample size using an alpha of 0.05 , power of 0.95 , odds ratio of 1.3 , and one-tail test. The analysis assumes that all dependent variables are log-normally distributed. Based on those assumptions, the desired sample size is 221. Secondly, we calculated the sample size using Whitehead's formula, which is based on the proportional odds model. Using this formula, the maximum sample size among the nine dependent variables is 192 participants [60-62]. A third method involves using Hmisc R Package ( $\mathrm{R}$ Core Team (2017). R: A language and environment for statistical computing. R Foundation for Statistical Computing, Vienna, Austria) with two power values (0.90 and 0.80 ) resulting in a maximum sample size of 280 (Power $=90 \%$ ) and 209 (Power $=80 \%$ ). The last method we used to determine sample size involves using a rule of thumb. The number of event per variable is at least 20-50, as suggested by van der Ploeg et al. [63]. Therefore, our five-level independent variable model indicates that 100-250 participants are required as a sample size. Based on the four approaches above, we can 
conclude that our experiment sample size (326) is well-above all calculated sample sizes, and thus it is sufficient for our model analysis.

\subsection{Using Principal Component Analysis to Reduce Well-Being Data and Compare with Well-Being Measures} Selected Based on the Literature

The survey contains 24 (out of 60) questions that can directly measure well-being [49]. Principal Component Analysis (PCA) was used to reduce these 24 questions of well-being while retaining as much as possible the variance in the data. Four significant components (those whose eigenvalue is higher than 1) were selected, accounting for $59.78 \%$ of the variance. The oblique rotation of standardized component loadings shows that the data load clearly on four components. As shown in Table 2, component 1 describes the loading of positive well-being items (both evaluative and hedonic) and it accounted for $42.4 \%$. Component 2 accounted for $6.6 \%$ and is characterized by negative well-being items. Components 3 and 4 accounted for $5.8 \%$ and $4.97 \%$ of the variance, respectively. They are characterized by other well-being items that are related to being tired and trust. The results from the PCA analysis are in good agreement with the nine selected measures of well-being. Six of the nine measures fall in the group of items loaded on component 1 . All six measures are positive well-being measures. The other three selected well-being measures fall into group two, where items loaded on component 2 . The three measures are recent negative well-being measures.

Table 2. Pattern matrix of four-component principal component analysis (PCA) solution with oblique rotation of 24 well-being measures.

\begin{tabular}{|c|c|c|c|c|}
\hline \multirow{2}{*}{ Items of Well-Being } & \multicolumn{4}{|c|}{ Component } \\
\hline & 1 & 2 & 3 & 4 \\
\hline Satisfaction with how life turned out & 0.725 & & & \\
\hline General happiness & 0.721 & & & 0.366 \\
\hline Optimistic & 0.675 & & & \\
\hline Satisfaction with life nowadays & 0.661 & & & 0.381 \\
\hline My life is close to how I would like it to be & 0.624 & & & \\
\hline Satisfaction with standards of living & 0.620 & & & 0.362 \\
\hline Enjoyed life recently & 0.619 & & & \\
\hline Feeling positive & 0.611 & & & \\
\hline My life valuable & 0.584 & & & \\
\hline Feeling a sense of accomplishment & 0.564 & & & -0.308 \\
\hline Recently happy & 0.525 & & & \\
\hline Feeling close to people in my area & 0.487 & & 0.307 & \\
\hline Recently sad & & 0.762 & & \\
\hline Recently bored & & 0.732 & & \\
\hline Recently lonely & & 0.723 & & \\
\hline Recently depressed & & 0.680 & & \\
\hline Recently feeling powerless & & 0.636 & & \\
\hline It takes me a long time to get back to normal & & 0.546 & & \\
\hline I am a failure & 0.335 & 0.401 & & \\
\hline Recently my sleep has been restless & & & 0.726 & \\
\hline Recently feeling tired & & & 0.720 & \\
\hline Recently I woke up rested & 0.355 & & 0.684 & \\
\hline Most people cannot be trusted & & & & 0.662 \\
\hline Recently everything I did was an effort & -0.301 & 0.456 & 0.339 & 0.469 \\
\hline
\end{tabular}

Extraction Method: Principal Component Analysis. Rotation Method: Oblimin with Kaiser Normalization.

PCA was also performed on the nine selected well-being measures themselves. Table 3 shows that three components explain $77 \%$ of the variance. The oblique rotated solution effectively separates the data into evaluative positive well-being items loading on component 1 , negative hedonic well-being items loading on component 2, and positive hedonic well-being items loading on component 3 . The question, all things considered, how satisfied are you with life as a whole nowadays?, loaded on component 
1 with the evaluative well-being items. This is not totally unexpected as nowadays could be thought of as an extend period of time other than recent time. The classification of the nine measures into three groups agrees with the classification from the literature.

Table 3. Pattern matrix of three-component PCA solution with oblique rotation of the nine selected well-being measures.

\begin{tabular}{|c|c|c|c|}
\hline \multirow{2}{*}{ The Nine Selected Items of Well-Being } & \multicolumn{3}{|c|}{ Component } \\
\hline & 1 & 2 & 3 \\
\hline General happiness & 0.879 & & \\
\hline Satisfaction with standards of living & 0.867 & & \\
\hline Satisfaction with life nowadays & 0.857 & & \\
\hline Satisfaction with how life turned out & 0.830 & & \\
\hline Recently feeling powerless & & 0.904 & \\
\hline Recently sad & & 0.786 & \\
\hline Recently depressed & & 0.712 & \\
\hline Recently happy & & & -0.920 \\
\hline Enjoyed life recently & & & -0.771 \\
\hline
\end{tabular}

\subsection{Chi-Squared Test between SWB Measures and the Independent Variables}

Table 4 shows a summary of the Chi-squared test for independence between all SWB measures and the independent variables. Seven SWB measures were associated with employment, while six measures were associated with gender. The binary age variable did not show significant association with SWB measures, except with recent powerlessness. Both perceived odor and odor acceptability associated with all EWB measures, recent satisfaction, and recent sadness.

Table 4. Chi-squared test for independence between all subjective well-being (SWB) measures and the independent variables.

\begin{tabular}{|c|c|c|c|c|}
\hline Investigated Variables & Chi-Squared $\left(\chi^{2}\right)$ & $\begin{array}{l}\text { Degrees of } \\
\text { Freedom }\end{array}$ & $p$ Value $^{1}$ & $\begin{array}{l}\text { Contingency } \\
\text { Assumption }\end{array}$ \\
\hline \multicolumn{5}{|l|}{ Happiness in general } \\
\hline Employment & 11.6 & 4 & $0.02 *$ & $<20 \%$ \\
\hline Gender & 12.9 & 4 & $0.01 *$ & $<20 \%$ \\
\hline Age & 4.18 & 4 & 0.38 & $20 \%$ \\
\hline Perceived odor & 30.9 & 16 & $0.01 *$ & $>20 \%$ \\
\hline Odor acceptability & 16.6 & 8 & $0.03 *$ & $20 \%$ \\
\hline \multicolumn{5}{|c|}{ Satisfaction with how life turned out } \\
\hline Employment & 16.52 & 4 & $0.002 *$ & $<20 \%$ \\
\hline Gender & 12.1 & 4 & $0.02 *$ & $<20 \%$ \\
\hline Age & 3.95 & 4 & 0.41 & $20 \%$ \\
\hline Perceived odor & 30.4 & 16 & $0.02 *$ & $>20 \%$ \\
\hline Odor acceptability & 16.9 & 8 & $0.03 *$ & $20 \%$ \\
\hline \multicolumn{5}{|c|}{ Satisfaction with standards of living } \\
\hline Employment & 11.67 & 4 & $0.02 *$ & $<20 \%$ \\
\hline Gender & 5.3 & 4 & 0.26 & $<20 \%$ \\
\hline Age & 2.44 & 4 & 0.66 & $<20 \%$ \\
\hline Perceived odor & 26.8 & 16 & $0.04 *$ & $>20 \%$ \\
\hline Odor acceptability & 23.0 & 8 & $0.003 *$ & $<20 \%$ \\
\hline \multicolumn{5}{|l|}{ Satisfaction with life nowadays } \\
\hline Employment & 19.1 & 4 & $0.0007 *$ & $<20 \%$ \\
\hline Gender & 5.8 & 4 & 0.22 & $<20 \%$ \\
\hline Age & 3.84 & 4 & 0.43 & $<20 \%$ \\
\hline Perceived odor & 43.6 & 16 & $0.0002 *$ & $>20 \%$ \\
\hline Odor acceptability & 17.6 & 8 & $0.02 *$ & $20 \%$ \\
\hline
\end{tabular}


Table 4. Cont.

\begin{tabular}{|c|c|c|c|c|}
\hline Investigated Variables & Chi-Squared $\left(\chi^{2}\right)$ & $\begin{array}{l}\text { Degrees of } \\
\text { Freedom }\end{array}$ & $p$ Value $^{1}$ & $\begin{array}{l}\text { Contingency } \\
\text { Assumption } 2\end{array}$ \\
\hline \multicolumn{5}{|l|}{ Recent enjoyment } \\
\hline Employment & 1.69 & 3 & 0.6 & $<20 \%$ \\
\hline Gender & 13.7 & 3 & $0.003 *$ & $<20 \%$ \\
\hline Age & 4.24 & 3 & 0.24 & $<20 \%$ \\
\hline Perceived odor & 14.9 & 12 & 0.25 & $>20 \%$ \\
\hline Odor acceptability & 3.23 & 6 & 0.78 & $<20 \%$ \\
\hline \multicolumn{5}{|l|}{ Recent happiness } \\
\hline Employment & 2.79 & 3 & 0.4 & $<20 \%$ \\
\hline Gender & 9.4 & 3 & $0.024 *$ & $<20 \%$ \\
\hline Age & 3.70 & 3 & 0.30 & $<20 \%$ \\
\hline Perceived odor & 12.9 & 12 & 0.38 & $>20 \%$ \\
\hline Odor acceptability & 5.22 & 6 & 0.52 & $>20 \%$ \\
\hline \multicolumn{5}{|l|}{ Recent depression } \\
\hline Employment & 7.9 & 3 & $0.048 *$ & $<20 \%$ \\
\hline Gender & 13.6 & 3 & $0.004 *$ & $<20 \%$ \\
\hline Age & 5.52 & 3 & 0.14 & $<20 \%$ \\
\hline Perceived odor & 14.3 & 12 & 0.28 & $20 \%$ \\
\hline Odor acceptability & 11.9 & 6 & 0.06 & $<20 \%$ \\
\hline \multicolumn{5}{|l|}{ Recent powerlessness } \\
\hline Employment & 13.5 & 3 & $0.004 *$ & $<20 \%$ \\
\hline Gender & 8.7 & 3 & $0.034 *$ & $<20 \%$ \\
\hline Age & 8.19 & 3 & $0.04 *$ & $<20 \%$ \\
\hline Perceived odor & 7.5 & 12 & 0.82 & $>20 \%$ \\
\hline Odor acceptability & 1.04 & 6 & 0.98 & $<20 \%$ \\
\hline \multicolumn{5}{|l|}{ Recent sadness } \\
\hline Employment & 3.34 & 3 & 0.34 & $<20 \%$ \\
\hline Gender & 6.8 & 3 & $0.08 *$ & $<20 \%$ \\
\hline Age & 5.9 & 3 & 0.12 & $<20 \%$ \\
\hline Perceived odor & 8.5 & 12 & 0.75 & $>20 \%$ \\
\hline Odor acceptability & 10.5 & 6 & 0.1 & $<20 \%$ \\
\hline
\end{tabular}

${ }_{1, *}$ indicates significance; ${ }^{2}$ the percentage of number of cells that have expected frequencies less than five to the total number of cells in the contingency table.

Figure 2 shows boxplots of one SWB measure (satisfaction with how life turned out) for each independent variable. The difference between employed and unemployed participants is statistically significant $\left(\chi^{2}(4)=16.52, p<0.002\right)$ in favor of employment. Female participants had statistically significant associations with higher satisfaction with how life turned out than male participants $\left(\chi^{2}(4)=12.1, p<0.02\right)$. No significant difference was found between the Above 45 years old group and the 45 or below group $\left(\chi^{2}(4)=3.95, p<0.41\right)$. We found statistically significant differences between perceived odor outcomes $\left(\chi^{2}(16)=30.35, p<0.016\right)$ and between odor acceptability outcomes $\left(\chi^{2}(8)=16.85, p<0.03\right)$. The chi-squared test does not quantify the association between satisfaction with how life turned out and the independent variables (employment, gender, perceived odor, and odor acceptability). To quantify the association between the nine SWB measures and the independent variables, an ordinal logistic regression was used. 

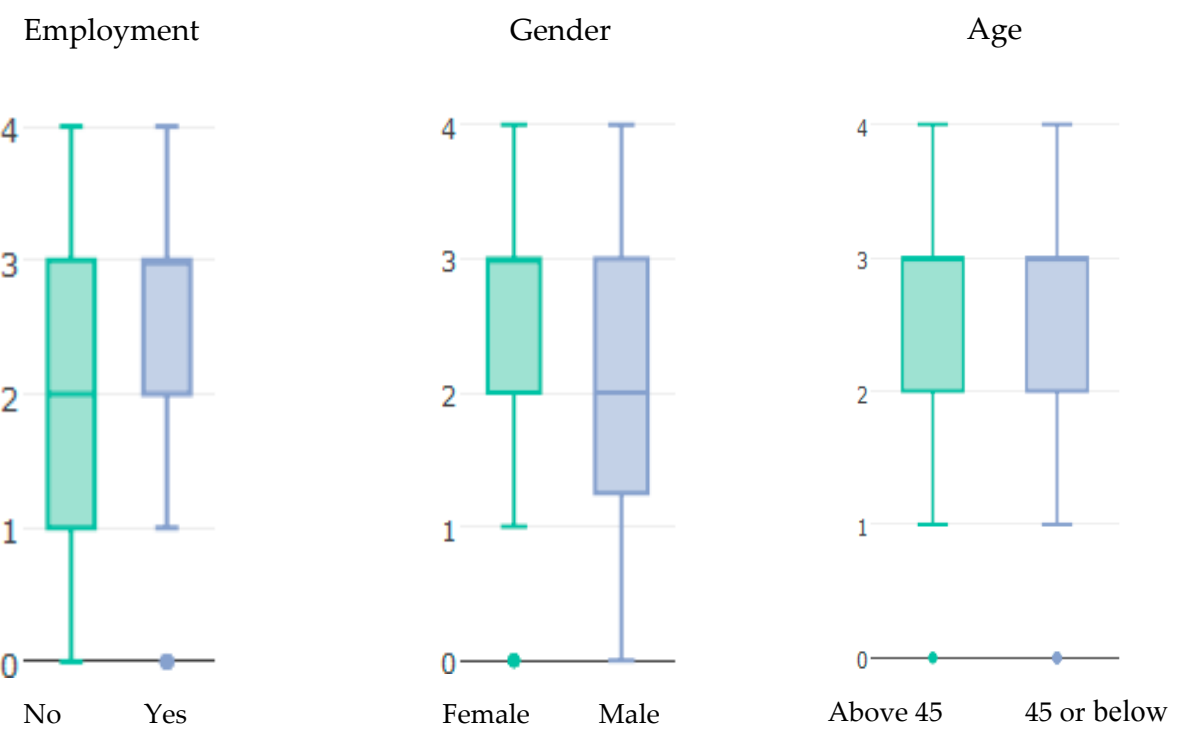

Perceived odor

Odor acceptability
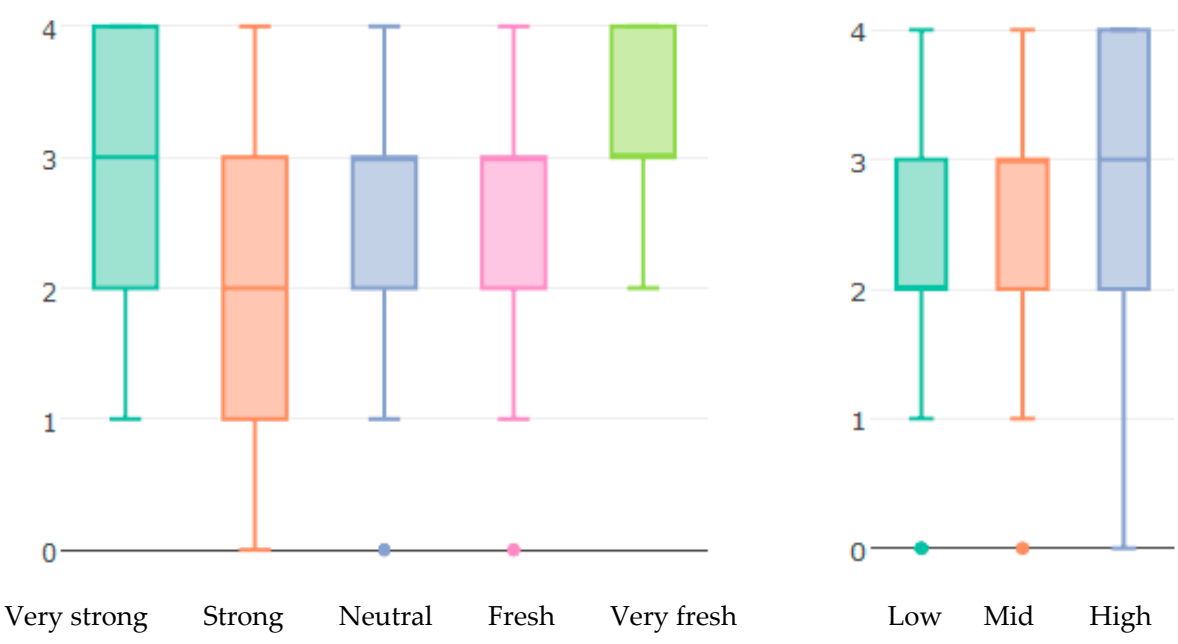

Figure 2. The effect of employment, gender, age, perceived odor, and odor acceptability on one subjective well-being (SWB) measure: satisfaction with how life turned out. $Y$-axis is the score of satisfaction with how life turned out, where 4 indicates the highest level of satisfaction and 0 indicates the lowest level of satisfaction.

\subsection{Ordinal Logistic Regression Results}

A total of 351 participants joined the study and submitted the online survey (100 from Greeley, 40 from Fort Lupton, 62 from North Denver, 117 from Pueblo, 22 from Fort Collins, and 10 from LaSalle). This number of participants was reduced to 326 by excluding surveys from outside the five communities and repeated surveys when they were identified. The weighted sample was $25 \%$ male and all participants were at least 18 years of age (19\% aged $18-25,37 \%$ aged $26-35,26.5 \%$ aged $36-45$, $11 \%$ aged $46-55,5.5 \%$ aged $56-65,0.5 \%$ aged $66-75$, and $0.5 \%$ aged $76-85)$. To avoid the effect of small numbers of participants in certain groups of age, the variable age was dichotomized at the median [64].

The proportional odds logistic regression model was used to estimate associations between the five independent variables and measures of SWB at the conventional 5\% level of significance. The results from the proportional odds model are obtained in the form of odds ratios (ORs), which are presented graphically as forest plots in Figure 3. The values on the $x$-axis are the ORs obtained from the 
proportional odds regression model output. The increase in OR values in the forest plots indicates better SWB and confidence intervals excluding one are considered significant.

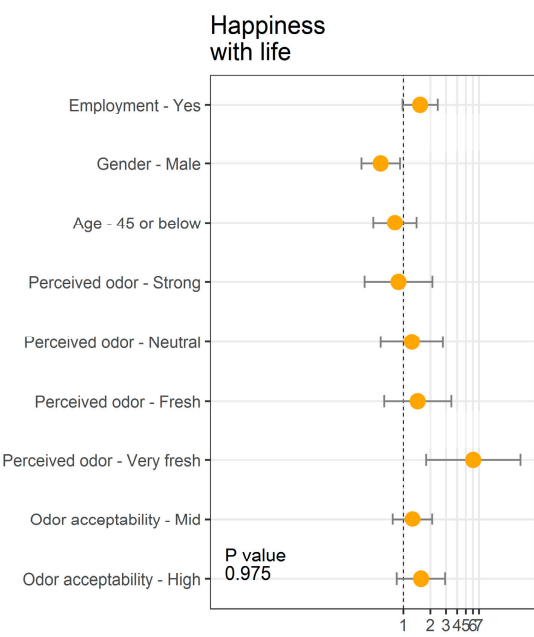

Odds ratio (log scale)
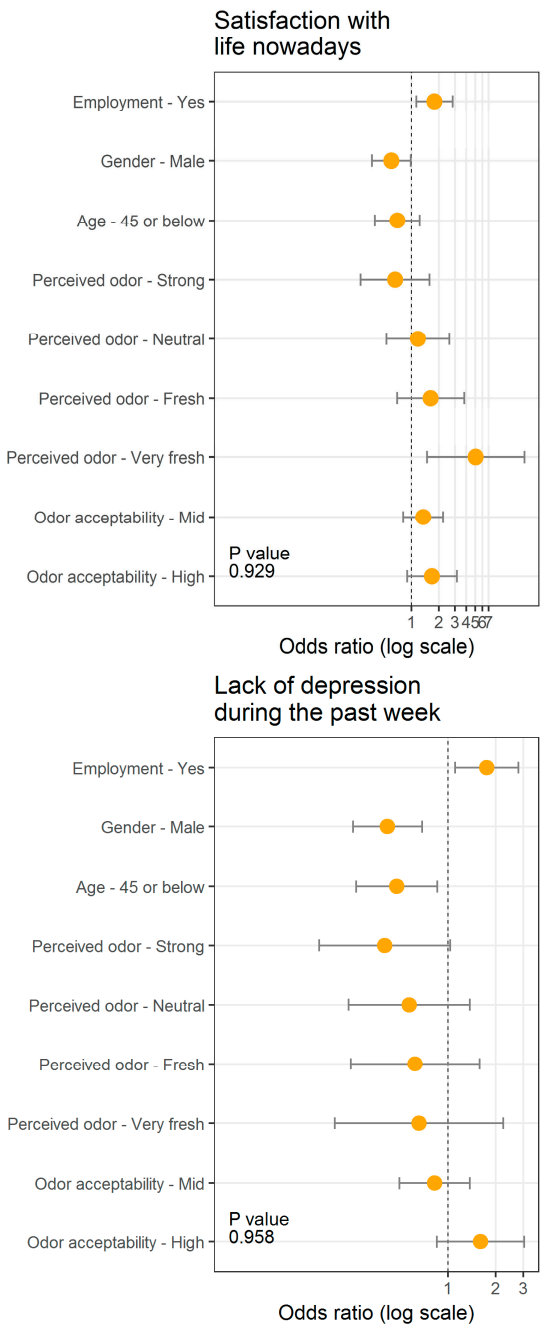

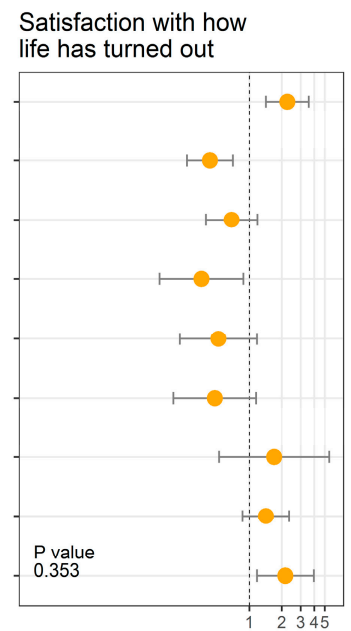

Odds ratio (log scale)

Enjoyed life during

the past week

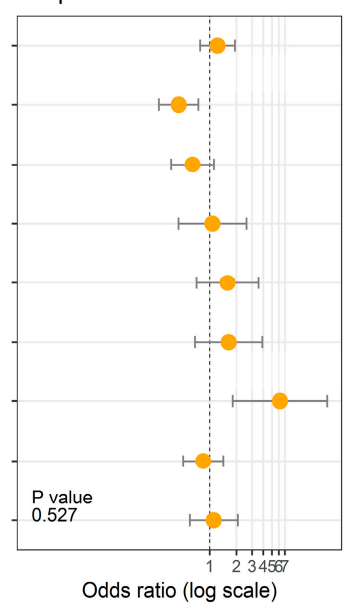

ack of powerlessness during the past week

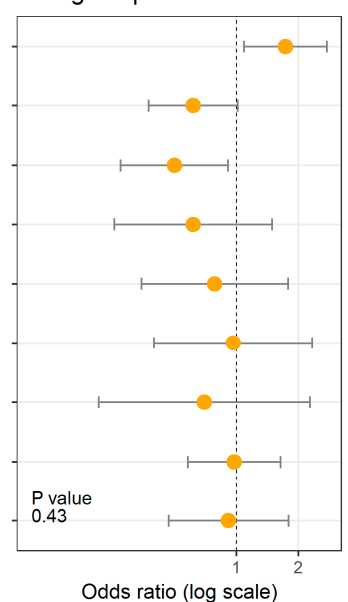

Satisfaction with standard of living

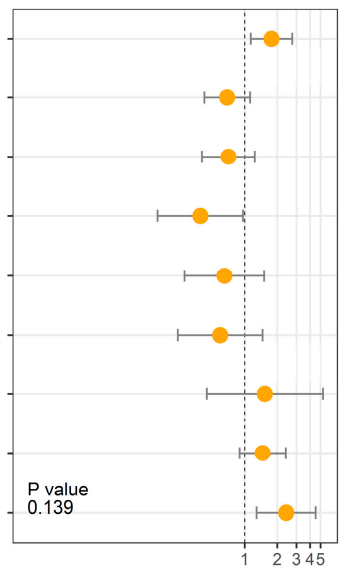

Odds ratio (log scale)

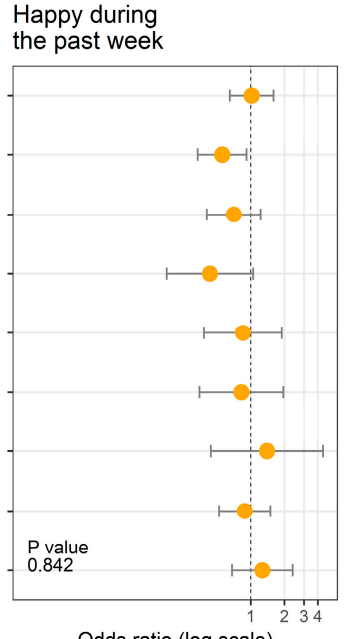

Odds ratio (log scale)

Lack of sadness

during the past week

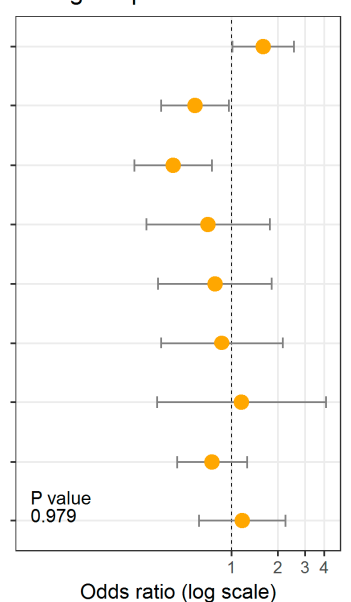

Figure 3. Forest plots of the effects of the five independent variables on the measures of subjective well-being. 


\subsubsection{Well-Being and Employment}

The proportional odds model results indicate that the three measures of satisfaction and $-\mathrm{HWB}$ measures were associated with employment. The OR of $2.25(95 \% \mathrm{CI}=1.43-3.56)$, OR of 1.76 $(95 \% \mathrm{CI}=1.14-2.74)$, and OR of $1.79(95 \% \mathrm{CI}=1.13-2.84)$ suggest that employed participants tended to have higher levels of satisfaction with how life turned out, satisfaction with standards of living, and recent satisfaction, respectively. Similarly, the OR of $1.76(95 \% \mathrm{CI}=1.11-2.79)$, OR of 1.73 $(95 \% \mathrm{CI}=1.09-2.76)$, and OR of $1.60(95 \% \mathrm{CI}=1.03-2.54)$ suggest that employed participants reported higher levels of lack of recent depression, recent powerlessness, and recent sadness, respectively. It is probably worth mentioning that higher levels of lack of a well-being (WB) measure has the same meaning as lower levels of that WB measure. These results are in good agreement with the strong evidence in the literature of the negative impact of unemployment on SWB [28,30-32,65-67]. Other studies that measured SWB based on psychological distress and depression [68,69] also showed that SWB was negatively correlated with unemployment. Those results are also in good agreement with our findings that indicate lower levels of $-\mathrm{HWB}$ are correlated with employment.

\subsubsection{Well-Being and Gender}

Male participants tended to have lower levels of SWB. Precisely, male participants had lower levels of general happiness (OR of $0.56 ; 95 \% \mathrm{CI}=0.34-0.92$ ), and satisfaction with how life turned out (OR of $0.43 ; 95 \% \mathrm{CI}=0.27-0.70$ ). Measures of $+\mathrm{HWB}$ are significantly associated with gender. The OR of $0.60(95 \% \mathrm{CI}=0.37-0.98)$, OR of $0.45(95 \% \mathrm{CI}=0.27-0.75)$, and $\mathrm{OR}$ of $0.56(95 \% \mathrm{CI}=0.34-0.92)$ indicate that males had a lower level of recent satisfaction, recent enjoyment, and recent happiness, respectively. Male participants also had higher levels of recent depression ( $\mathrm{OR}$ of $0.41 ; 95 \% \mathrm{CI}=0.25-0.68)$ and recent sadness (OR of $0.58 ; 95 \% \mathrm{CI}=0.35-0.97$ ).

According to the literature, the gender impact on SWB seems to lack consistency. A number of studies $[68,70]$ showed that gender has no effect on SWB, while other studies showed that gender correlated with SWB. Some studies that found females are more likely to have higher well-being than males [71,72]. In contrast, other studies found that women have lower levels of SWB [73], and higher levels of stress, worry, and sadness [36], and tend to be more critical of themselves than men [65]. The same study by Stone et al. [36] found that women reported higher evaluative well-being. A study conducted by Wu et al. [74] investigated mental health and suicidal thoughts among 1848 pilots, and concluded that higher levels of depression were found among pilot women than among pilot men. The same study also found that women tended to report more days of poor mental health than men. According to the U.S. Centers for Disease Control and Prevention, women experience depression more than men in the United States. Flatau et al. [32] found that both incidences and attempts of suicidal thoughts were higher among women.

\subsubsection{Well-Being and Age}

The binary variable of age, 45 years old or below and Above 45 years old, showed significant association with only the measures of - HWB. The participants who were aged 45 or below had nearly half the odds of those who were above 45 years old. The OR of 0.47 ( $95 \% \mathrm{CI}=0.26-0.85$ ), OR of $0.50(95 \% C I=0.27-0.91)$, and OR of $0.42(95 \% \mathrm{CI}=0.24-0.75)$ indicate that participants aged 45 years old or below had higher levels of recent depression, recent powerlessness, and recent sadness, respectively. The measures of both EWB and + HWB did not show significant association with binary age. We decided to use a dichotomized age variable because the number of participants in some age groups was not sufficient [64]. The weighted sample of the binary variable was $82 \%$ aged 45 years old or below and $18 \%$ above 45 years old. Our findings about - HWB with the binary age seem to be consistent with the findings of Steptoe et al. [35], who found that elderly people, despite their health challenges, seem to experience less stress, worry, and anger. Typically, however, in the studies that investigated the impact of age on SWB, age is used as a continuous variable. Most of those studies 
indicated that age has a U-shaped effect on EWB, particularly on general happiness $[28,30,35,65,75,76]$. Our findings are still in partial agreement with the $\mathrm{U}$-shaped results, as the EWB and +HWB increase after the age of 50 years old $[35,65]$.

\subsubsection{Well-Being and Perceived Odor}

Almost all measures of EWB and +HWB showed a strong association with perceived odor, while $-\mathrm{HWB}$ measures did not show significant association. The OR of $6.06(95 \% \mathrm{CI}=1.80-20.40)$, OR of $5.08(95 \% \mathrm{CI}=1.49-17.33)$, and OR of $6.16(95 \% \mathrm{CI}=1.81-20.91)$ suggest that the participants who reported that the air was very fresh had higher levels of general happiness, recent satisfaction, and recent enjoyment, respectively. Correspondingly, the OR of $0.36(95 \%, \mathrm{CI}=0.15-0.88)$ and OR of $0.39(95 \%, \mathrm{CI}=0.16-0.97)$ suggest that the participants who reported that the air had strong odor (smelly) had lower levels of satisfaction with how life turned out and satisfaction with standards of living, respectively. Recent happiness is the only measure of $+\mathrm{HWB}$ that did not show significant association with perceived odor.

\subsubsection{Well-Being and Odor Acceptability}

Satisfaction with how life turned out and satisfaction with standards of living were associated with odor acceptability. The OR of $2.16(95 \%, C I=1.18-3.97)$ and OR of $2.41(95 \%, C I=1.29-4.49)$ suggest that the participants who reported that odor was highly acceptable had higher levels of satisfaction with how life turned out and satisfaction with standards of living, respectively.

From the two previous sections, we can see that perceived odor was associated with five measures of SWB that represent EWB and +HWB. On the other hand, odor acceptability was associated with only two of measures that represent EWB. This association indicates that residents who lived in areas exposed to strong industrial odors (air has strong odor and low odor acceptability) had lower levels of EWB and + HWB. This lends support to previous findings in the literature, as summarized below.

The number of studies that linked well-being to odor exposure is limited. Some of these studies used psychological stress as a measure of well-being. In a study on health effects of odors from a petroleum refinery in Oakville, Ontario, Luginaah et al. [26] found that the decrease in odor exposure led to decrease in negative perception and concerns. The same study found an association between psychological reaction to general environmental stress and odor exposure. Another study found that hormones released in human body in response to stress were correlated with odorant exposure from a mushroom fertilizer production plant [40]. The association between stress and odor exposure was also confirmed in a cross-sectional study in animal research [41].

Other studies focused on the impact of odor exposure (mainly from animal production) on mental state indices such as depression, anger, confusion, tension, fatigue, and ability to focus. In a study about health and quality of life of residents from North Carolina near intensive livestock operations [77], it was found that residents who live near the swine operations experience reduced quality of life. Schiffman et al. [44] reported an association between unpleasant odors (from large hog operations) and mood state. The residents who were exposed the strong swine odors were most likely to have higher levels of depression, anger, fatigue, confusion, and tension when compared with residents who were not exposed to such odors. This is supported by the findings of Nordin et al. [45], who found that unpleasant odors had a negative impact on the ability to focus.

Our findings of the association between odor exposure, represented by perceived odor, with EWB, and $+\mathrm{HWB}$ agree with the reduction in quality of life and increase in general environmental stress caused by odor exposure found in previous studies $[26,40,77]$. The association between stress-related indices and well-being is also documented in the literature [78,79]. However, our findings are not in complete agreement with the studies that used mental state indices to measure well-being. These studies showed that odor exposure impacted negative hedonic well-being aspects such as stress, depression, anger, fatigue, confusion, and tension [44,45]. Although our findings showed a decrease in $-\mathrm{HWB}$ with the decrease in odor exposure, this association was not statistically significant. 
In odor exposure studies, the importance of evaluating the SWB based on the three aspects of EWB, $+\mathrm{HWB}$, and $-\mathrm{HWB}$ should not be overlooked. Using the three aspects produced different levels of association based on the odor exposure assessment method. While the odor exposure assessed by odor acceptability seem to be associated with evaluative well-being only, the odor exposure assessed by perceived odor was associated with both evaluative and hedonic well-being.

When interpreting our findings, it could be implied that four of our measures can be chosen to represent SWB (subjective well-being representatives, WB-Rep). Satisfaction with how life turned out, satisfaction with standards of living, recent satisfaction, and recent enjoyment are associated with both employment and perceived odor. They are associated with employment, which is known to be correlated with well-being measures. They are also associated with perceived odor, which is indicative of air quality. On the other hand, negative hedonic measures of SWB (depression, powerlessness, and sadness) may not be good representatives of SWB in communities affected by industrial odors. While they are associated with both employment and age, they did not show a significant association with perceived odor or odor acceptability.

\section{Additional Analyses}

\subsection{Potential Confounding Variables}

Our hypothesis is that people who live in industrial areas experience lower levels of SWB. One might argue that areas surrounding the industrial facilities are often communities of color and/or lower socioeconomic communities. In the context of this argument, residents of those communities have lower levels of well-being because of other factors, such as level of education or income. In other words, the hypothesized association might be influenced by some third confounding variable. In this section, we investigated the effect of potential confounding variables. Diener et al. [38] pointed out that sociodemographic factors and social relationships must be considered when we examine potential confounders in SWB-related studies. Our list of the target variables that could be potential confounders includes three binary variables and four ordinal variables. Table 5 details the outcomes of each target variable.

Table 5. Target variables and their outcomes.

\begin{tabular}{ccc}
\hline Variable & Type & Outcomes \\
\hline Employment & Binary & Yes/No \\
\hline Age & Binary & 45 or below/Above 45 \\
\hline Gender & Binary & Male/Female \\
\hline Education & Ordinal & $\begin{array}{r}\text { Below high school/High school graduate/Some college credit, } \\
\text { No degree/Bachelor's degree/Graduate level }\end{array}$ \\
\hline Income & Ordinal & $\begin{array}{c}\text { Less than } 25,000 / 25,000 \text { to } 34,999 / 35,000 \text { to } 49,999 / 50,000 \text { to } \\
74,999 / 75,000 \text { to } 99,999 / 100,000 \text { to } 149,999 / 150,000 \text { or more }\end{array}$ \\
\hline Marital status & Ordinal & $\begin{array}{c}\text { Single, never married/Married or Domestic } \\
\text { partnership/Separated/Widowed/Divorced }\end{array}$ \\
\hline Race & Ordinal & White/Hispanic or Latino/Other \\
\hline
\end{tabular}

A confounder variable is a variable that was not accounted for (not included in the model), which can bias the model results and lead to incorrect conclusions. In order for a variable to be a confounder, (1) it must be predictive of the dependent variable; (2) it must be correlated with the independent variable; (3) it must be unequally distributed between treatment groups; and (4) it must not be a link in the causal chain $[80,81]$.

The ordinal logistic regression model showed that perceived odor was associated with happiness, satisfaction with how life turned out, satisfaction with standards of living, recent satisfaction, and recent enjoyment. It also showed that odor acceptability was associated with satisfaction with how life turned 
out and satisfaction with standards of living. The goal was to test whether the target variable correlated with the dependent variables (condition 1) and with the independent variables (condition 2).

Table 6 reports $p$-values from the chi-square test for independence between target variables and variables of interest (both independent and dependent). Except for gender, all target variables are not confounders because they do not meet condition (1). Gender seems to be associated only with perceived odor $(p=0.04)$. When we further test condition (2) for gender, we can see that gender is also associated with happiness $(p=0.012)$, satisfaction with how life turned out $(p=0.017)$, and recent enjoyment $(p=0.003)$. This indicates that gender is a potential confounder of perceived odor, because it is not equally distributed and obviously it is not on the causal chain between perceived odor and the SWB measures. Many studies found that gender is a potential confounder $[82,83]$.

Table 6. Association between target variables and both dependent and independent variables.

\begin{tabular}{|c|c|c|c|c|c|c|c|}
\hline \multirow[b]{2}{*}{$\begin{array}{c}\text { Target } \\
\text { Variable }\end{array}$} & \multicolumn{2}{|c|}{ Association with Independent Variables } & \multicolumn{5}{|c|}{ Association with the Dependent Variables } \\
\hline & $\begin{array}{l}\text { Association with } \\
\text { Perceived Odor }\end{array}$ & $\begin{array}{l}\text { Association with } \\
\text { Odor Acceptability }\end{array}$ & $\begin{array}{l}\text { General } \\
\text { Happiness }\end{array}$ & $\begin{array}{c}\text { Satisfaction with } \\
\text { How Life } \\
\text { Turned Out }\end{array}$ & $\begin{array}{c}\text { Satisfaction with } \\
\text { Standards } \\
\text { of Living }\end{array}$ & $\begin{array}{l}\text { Satisfaction } \\
\text { with Life } \\
\text { Nowadays }\end{array}$ & $\begin{array}{c}\text { Enjoy Life } \\
\text { Recently }\end{array}$ \\
\hline Gender & 0.04 & 0.095 & 0.012 & 0.017 & 0.26 & 0.22 & 0.003 \\
\hline Employment & 0.47 & 0.67 & 0.02 & 0.002 & 0.02 & 0.0008 & 0.64 \\
\hline Education & 0.74 & 0.53 & 0.023 & 0.008 & 0.036 & 0.014 & 0.86 \\
\hline Race & 0.31 & 0.41 & 0.15 & 0.62 & 0.81 & 0.32 & 0.67 \\
\hline
\end{tabular}

One way to control for confounding effects in analysis is by using a multivariable model (proportional odds regression, in our case), which assesses the hypothesized relationship, and at the same time, adjusting for the potential confounder, age. Consequently, ORs from our model were adjusted for age. The model also has two odor-related variables of interest and two binary demographic variables in order to compare with the literature. Regardless of which of the independent variables is a confounder or an exposure (variable of interest), the model treats all variables the same way [84].

\subsection{Composite Scoring}

We combined our measures of SWB to formulate a single measure and compared it with well-known, reliable, and tested SWB measures already in the literature. From the proportional odds regression conducted in this study, we hypothesized that SWB can be well represented by four measures (satisfaction with how life turned out, satisfaction with standards of living, recent satisfaction, and recent enjoyment). We used the total score (composite score) of the four measures as a subjective well-being representative (WB-Rep). The possible answers of each of the four questions are scored on a scale ranging from 0 to 4 . The total composite scores of our WB-Rep, therefore, will be 0 to 16 points [74]. Figure 4 shows a comparison between composite scores of ONS, SWEMWBS, and WB-Rep. The three measures are consistent and show higher levels of well-being for employed and female participants. The three measures also indicate that the well-being levels increase when perceived odor decreases. The WB-Rep positively correlates with ONS $\left(r=0.78, n=326, p<2.2 \times 10^{-16}\right)$, as well as with SWEMWBS $\left(r=0.74, n=326, p<2.2 \times 10^{-16}\right)$.

A scatter plot between the total composite scores of SWB explanatory questions and SWB measures $\left(r=0.81, n=326, p<2.2 \times 10^{-16}\right)$ is shown in Figure 5. It is worth mentioning that the classification above included only 49 questions (out of 60 questions). The following questions were excluded: the seven demographic questions, a question about odor type, a binary question about employment, a binary question about having someone to discuss matters with, and a question about how many times a participant meets with family and friends. A few other assumptions have been made only for this section's analysis. To avoid deleting a large number of the dataset, all missing values and values that identified as Don't know were replaced with the value "2" $[85,86]$. The purpose of this demonstration 
was to show that the classification of NEFs survey questions to explanatory and response questions (measures) can be useful for future studies.
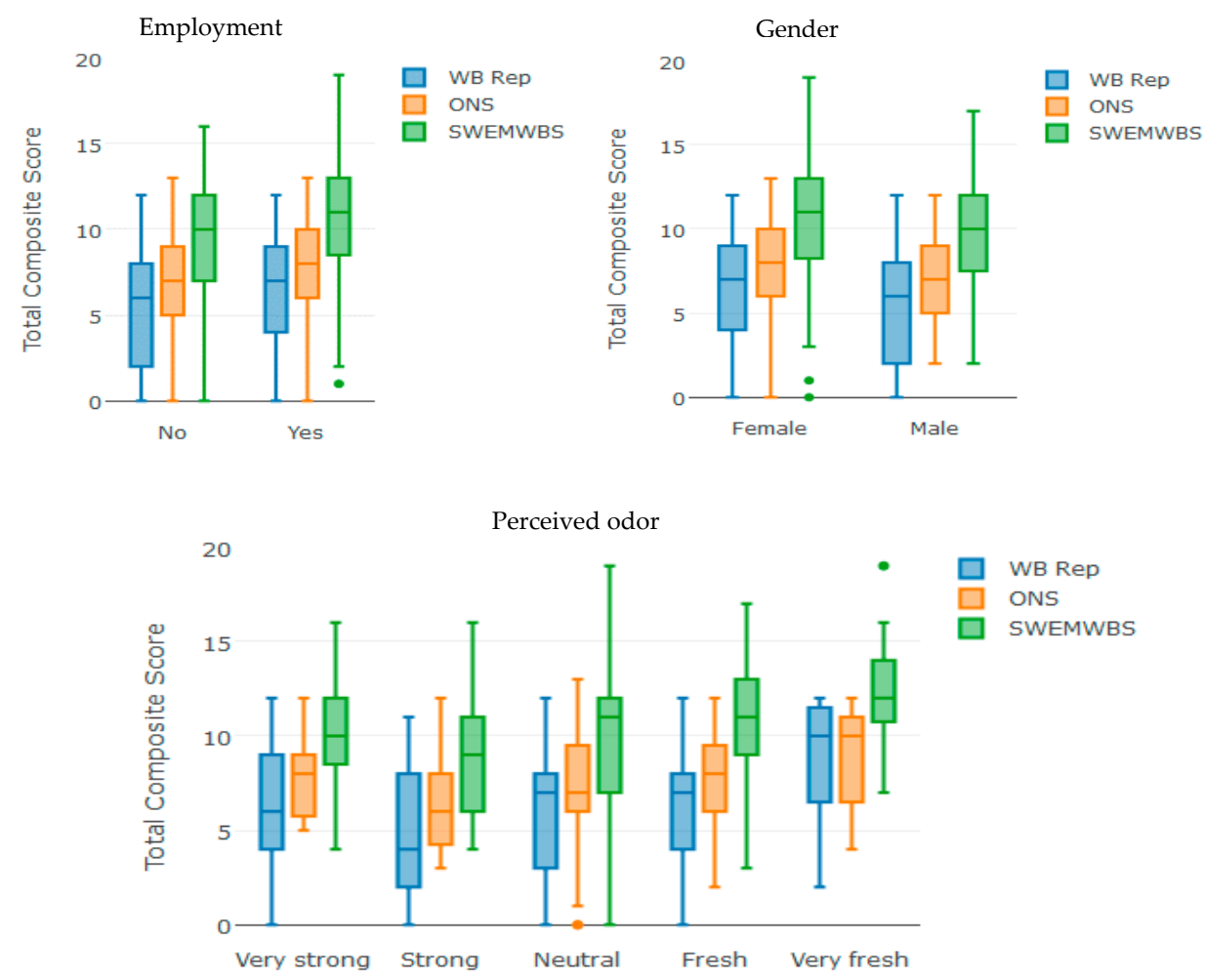

Figure 4. Comparison between subjective well-being representative (WB-Rep), Office for National Statistics (ONS), and Short Warwick-Edinburgh Mental Well-being Scale (SWEMWBS).

Total Dependent Variables vs. Total Independent Variables

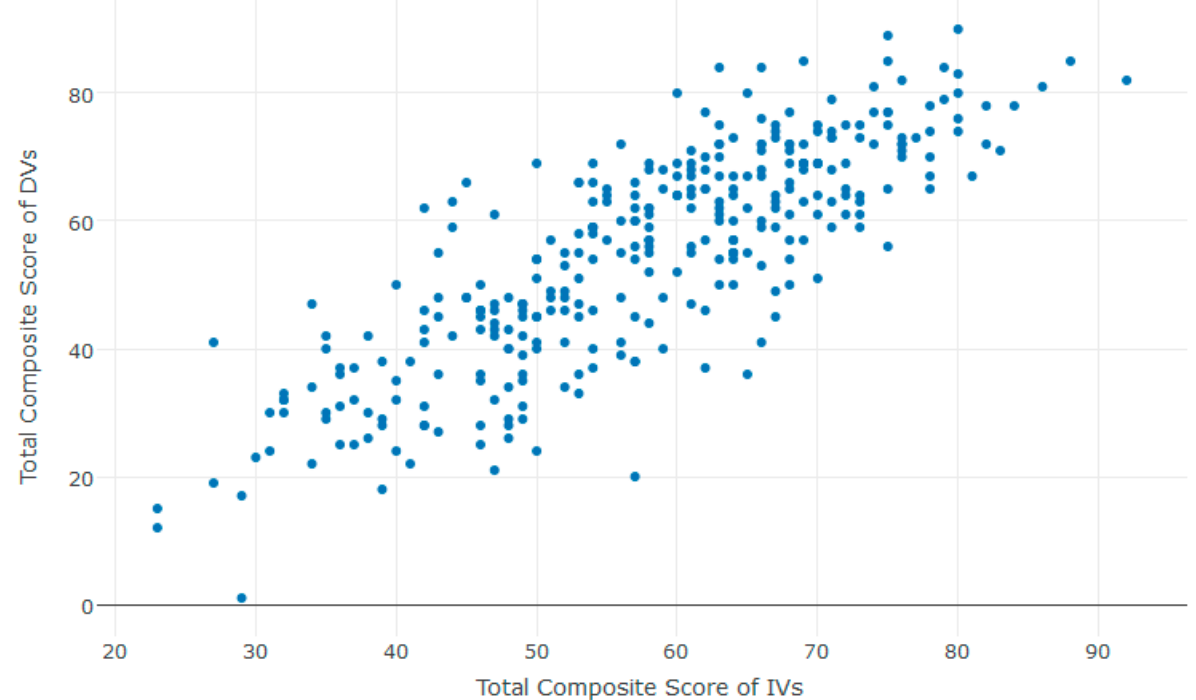

Figure 5. Scatter plot between the total composite scores of SWB explanatory questions and SWB measures. DVs—dependent variables; IVs—independent variables.

\subsection{Seasonal Effect on Well-Being}

We analyzed the longitudinal data that were collected by asking participants to take the survey four times during one year (once every three months) in order to see if WB changed from season to 
season. A total of 55 people took the survey at least twice during the period of time from March 2016 to June 2017. In detail, thirty-six people (65\%) took the survey twice, 14 people (26\%) took the survey three times, and only 5 people (9\%) took the survey four times. The following analysis was conducted on 134 responses.

We divided the year to four quarters. The first quarter includes January, February, and March. The second includes April, May, and June. The third includes July, August, and September. The fourth includes October, November, and December. There were 38 responses in the first quarter, 41 in the second, 37 in the third, and 18 in the last quarter.

Because the sample size in this longitudinal analysis was very small, the contingency table analysis assumption was violated. That is, the number of cell values (expected frequencies) that are less than five $(<5)$ exceeded the conditional limit of $20 \%$ (see Table S4). Therefore, all SWB measures were converted to binary variables (e.g., satisfied or not-satisfied). Table 7 shows results from the chi-squared test of independence between season and the binary SWB measures. It can be seen that only two of SWB measures showed a weak association with seasonality-namely, satisfaction with how life turned out $\left(\chi^{2}(3)=9.3, p<0.03\right)$-and satisfaction with standards of living $\left(\chi^{2}(3)=7.7, p<0.05\right)$. Regardless of the weak association and small sample size, these results are not surprising. If SWB had a seasonal pattern, it would be expected that those patterns are more represented by EWB (global) measures than HWB (mood) measures. The chi-squared test does not quantify this weak association. However, boxplots (Figure 6) show that the participants have reported higher levels of the two types of satisfaction during the fourth quarter of the year (October, November, and December). The association between recent depression and seasonality, shown in Table 7, may not be correct because the contingency table analysis assumption was violated $(>20 \%)$.

Table 7. Relationship between season and the nine measures of subjective well-being. The results are from the chi-squared test, including $p$ value, chi test value, degree of freedom (DOF), and contingency assumption. All well-being (WB) measures are binary variables.

\begin{tabular}{|c|c|c|c|c|c|c|c|c|c|}
\hline $\begin{array}{l}\text { Chi Squared } \\
\text { Test for } \\
\text { Independence }\end{array}$ & $\begin{array}{l}\text { Happiness } \\
\text { in General }\end{array}$ & $\begin{array}{c}\text { Satisfaction } \\
\text { with How Life } \\
\text { Turned Out }\end{array}$ & $\begin{array}{c}\text { Satisfaction } \\
\text { with Standards } \\
\text { of Living }\end{array}$ & $\begin{array}{l}\text { Satisfaction } \\
\text { with Life } \\
\text { Nowadays }\end{array}$ & $\begin{array}{c}\text { Recent } \\
\text { Enjoyment }\end{array}$ & $\begin{array}{c}\text { Recent } \\
\text { Happiness }\end{array}$ & $\begin{array}{c}\text { Recent } \\
\text { Depression }\end{array}$ & $\begin{array}{c}\text { Recent } \\
\text { Power- } \\
\text { Lessness }\end{array}$ & $\begin{array}{l}\text { Recent } \\
\text { Sadness }\end{array}$ \\
\hline$p$-value & 0.25 & 0.03 & 0.05 & 0.33 & 0.2 & 0.07 & 0.00095 & 0.38 & 0.3 \\
\hline DOF & 3 & 3 & 3 & 3 & 3 & 3 & 3 & 3 & 3 \\
\hline $\begin{array}{l}\text { Contingency } \\
\text { assumption }\end{array}$ & $12.5 \%$ & $12.5 \%$ & $12.5 \%$ & $12.5 \%$ & $12.5 \%$ & $0 \%$ & $>20 \%$ & $0 \%$ & $12.5 \%$ \\
\hline
\end{tabular}

Satisfaction with standards of living

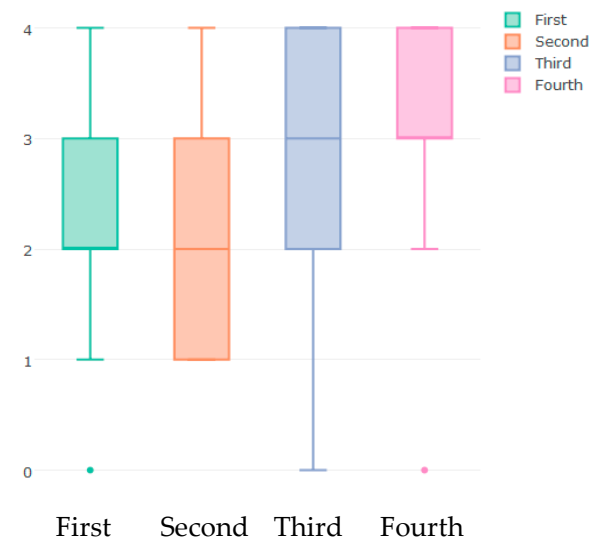

Satisfaction with how life turned out

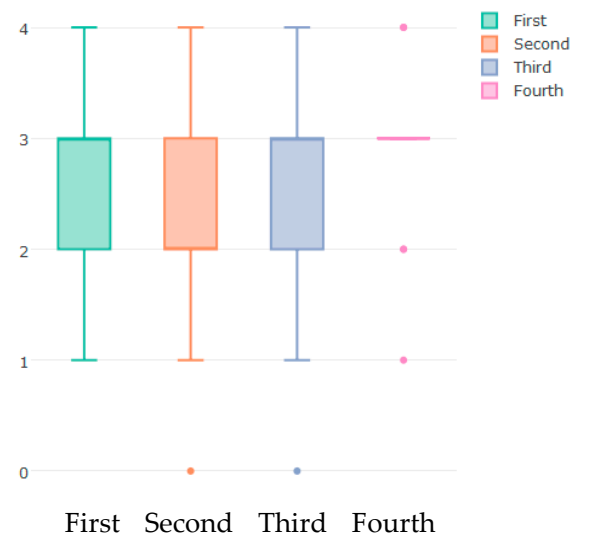

Figure 6. Seasonal variation in satisfaction with standards of living and satisfaction with how life turned out in five communities in Colorado. For both measures, a score of 4 indicates the highest level of satisfaction and a score of 0 indicates the lowest level of satisfaction. $X$-axis in both blots represents seasonal quarters of the year. 


\subsection{Well-Being in the Five Communities}

It was hypothesized that the North Denver and Greeley well-being would be different (lower) than the other communities because of the impact of industrial odors. A one-way Analysis of Variance (ANOVA) was conducted to compare the industrial odor levels in the five communities. There was a statistically significant difference between the five communities in regard to perceived odor $\left(\mathrm{F}(4,316)=7.02, \mathrm{P}=2 \times 10^{-6}\right)$. However, there was not a statistically significant difference between communities in odor acceptability levels. North Denver and Greeley clearly stand out as the most affected communities by industrial odors represented by perceived odor levels, as shown by the Tukey Post Hoc Test results in Table 8.

Table 8. The summary table of the Tukey Post Hoc Test results among communities' perceived odor. Only significant results are presented. ANOVA-Analysis of Variance.

\begin{tabular}{ccccc}
\hline $\begin{array}{c}\text { Industrial Odors Measure that Showed } \\
\text { Significant Difference between } \\
\text { Communities Based on ANOVA }\end{array}$ & $\begin{array}{c}\text { The Two Specific Locations that Showed } \\
\text { Significant Different Levels of Industrial } \\
\text { Odors Based on Tukey Post Hoc Test }\end{array}$ & Difference & $p$-Value \\
\hline & Location 1 & Location 2 & & \\
Perceived odor & Greeley & Fort Collins & $-0.7^{*}$ & 0.019 \\
& North Denver & Fort Collins & -0.66 & 0.045 \\
& Pueblo & Greeley & 0.60 & 0.0002 \\
& Pueblo & North Denver & 0.55 & 0.003 \\
\hline
\end{tabular}

* Negative sign in the difference column indicates that the first community (e.g., Greeley in the first row) has lower levels of perceived odor than the second community (e.g., Fort Collins).

Knowing the significant difference in industrial odor exposure (based on perceived odor levels), we need to answer the following question: are the overall well-being levels in North Denver and Greeley lower than in the other communities? One of the objectives of this work is to compare the well-being levels in the five communities (North Denver, Fort Collins, Fort Lupton, Greeley, and Pueblo).

An ANOVA was used to investigate the differences in the levels of the nine well-being measures between the five communities. The differences were statistically significant in four well-being measures: satisfaction with standards of living $(\mathrm{F}(4,316)=2.57, \mathrm{P}=0.04)$, satisfaction nowadays $(\mathrm{F}(4,318)=4.92, \mathrm{P}=0.0007)$, powerlessness $(\mathrm{F}(4,307)=3.104, \mathrm{P}=0.016)$, and sadness $(\mathrm{F}(4,310)=3.798$, $\mathrm{P}=0.005$ ). Since the ANOVA does not show which specific location (community) is different from the others, a Post Hoc Test, such as the Tukey Post Hoc Test, needs to be used. The results from the Tukey Post Hoc Test are presented in Table 9. All four well-being measures resulting from the ANOVA were lower in Pueblo than in Greeley. Additionally, Pueblo showed lower levels than North Denver in three well-being measures; satisfaction nowadays, recent powerlessness, and recent sadness. Lastly, Pueblo's satisfaction nowadays was also lower than Fort Lupton's. The difference in well-being levels between North Denver and the other communities was not statistically significant.

The proportional odds regression model showed a strong association between, for example, satisfaction with standard of living and satisfaction nowadays with perceived odor. However, from the ANOVA and Tukey Test analysis, the high levels of industrial odors in Greeley and North Denver did not lead to lower levels in the overall well-being in the two communities. In fact, the Tukey test implied that the overall well-being in North Denver is not different than the other communities (except Pueblo). One possibility is that some of the North Denver participants in this study were from neighborhoods that were more likely to be affected by industrial odors, such as Globeville and Elyria Swansea, while other participants were from neighborhoods that were less likely to be affected by industrial odors, such as Sloan Lake and Wheat Ridge. The analysis indicated that Pueblo's overall well-being levels were lower than all other communities. This might require an urgent, more detailed study to investigate the reasons behind this low level of well-being. 
Table 9. The summary table of the Tukey Post Hoc Test results among communities' well-being. Only significant results are presented.

\begin{tabular}{ccccc}
\hline $\begin{array}{c}\text { Well-Being Measure that Showed } \\
\text { Significant Difference between } \\
\text { Communities Based on ANOVA }\end{array}$ & $\begin{array}{c}\text { The Two Specific Locations that Showed } \\
\text { Significant Different Levels of well-Being } \\
\text { Based on Tukey Post Hoc Test }\end{array}$ & Difference & $p$-Value \\
\hline & Location $\mathbf{1}$ & Location $\mathbf{2}$ & & \\
Satisfaction with standard of living & Pueblo & Greeley & $-0.45^{*}$ & 0.042 \\
& Pueblo & Fort Lupton & -0.52 & 0.04 \\
Satisfaction Nowadays & Pueblo & Greeley & -0.39 & 0.03 \\
& Pueblo & North Denver & -0.58 & 0.0008 \\
Recent Powerlessness & Pueblo & Greeley & -0.33 & 0.05 \\
& Pueblo & North Denver & -0.38 & 0.03 \\
Recent Sadness & Pueblo & Greeley & -0.37 & 0.019 \\
& Pueblo & North Denver & -0.40 & 0.022 \\
\hline
\end{tabular}

${ }^{*}$ Negative sign in the difference column indicates that the first community (e.g., Pueblo in the first row) has lower levels of the well-being measure than the second community (e.g., Greeley).

\section{Conclusions}

Odor pollution was identified as a top priority of the community of North Denver. Previous studies that investigated the impact of air pollution in North Denver focused on air pollution sources and adverse health effects, rather than impact on mental well-being. In this study, we investigated whether odors from industrial sources impair the SWB of residents in North Denver and four communities in Colorado. To evaluate SWB in the five communities, nine measures from an online survey were used. The nine measures were grouped into three aspects: evaluative well-being, positive hedonic well-being, and negative hedonic well-being. This classification was based on recent studies and is in good agreement with the results from the PCA analysis. To the best of our knowledge, this approach of evaluating SWB has not been used in previous odor exposure studies. For every SWB measure, an ordinal logistic regression (in particular, a proportional odds regression) was used to quantify the relationship between that particular SWB measure and five independent variables. The five independent variables were employment, age, gender, perceived odor, and odor acceptability. The ordinal logistic regression we used showed that participants who were employed and female participants had higher levels of SWB. Almost all previous studies showed that unemployment had a strong negative impact on SWB. Our finding about the employment and SWB relationship was in good agreement with the literature. The impact of gender on SWB in the literature lacks consistency. However, our findings showed that female participants had higher levels of SWB. We also found that participants who were aged 45 or below had higher levels of recent depression, recent powerlessness, and recent sadness. Regarding the relationship between odor exposure and SWB, which is the aim of this study, we found that the participants who reported that the air is very fresh or odor is highly acceptable had higher levels of SWB. This association indicates that residents who live in areas exposed to strong industrial odors had lower levels of SWB. This lends support to previous findings in the literature, which indicated that unpleasant odors induced annoyance and general psychological stress, and reduced quality of life. While some studies showed that odor exposure (mostly from animal production) had an impact on mood state and ability to focus, our study did not show a significant association between odor exposure and negative hedonic well-being. Using the three aspects of EWB, $+\mathrm{HWB}$, and $-\mathrm{HWB}$ in odor exposure studies is important and should not be overlooked. Depending on the odor exposure assessment method, the association between odor exposure could be with one or two SWB aspects. While the odor exposure assessed by odor acceptability seems to be associated with evaluative well-being, the odor exposure assessed by perceived odor was associated with both evaluative and hedonic well-being.

We also found that four of our nine measures can be used to represent SWB in future studies. Two of those measures were evaluative SWB (satisfaction with how life turned out and satisfaction with standards of living) and the other two were positive hedonic SWB measures (satisfaction with 
life recently and recent enjoyment). The composite score of these four measures (named WB-Rep by us) showed good agreement with reliable, well-known, and tested SWB measures, namely ONS and SWEMWBS.

Longitudinal analysis showed that evaluative satisfaction was slightly associated with seasonality. Both satisfaction with how life turned out and satisfaction with standards of living slightly increased during the fourth quarter of the year (October to December).

A comparison between the five communities showed that well-being levels in North Denver and Greeley were not significantly different than in Fort Collins or Fort Lupton. The comparison, however, showed that Pueblo had the lowest levels of well-being among all communities.

Supplementary Materials: The following are available online at http:/ /www.mdpi.com/1660-4601/15/6/1091/ s1. Survey S1: The Industrial Odors and Well-being Questionaire. Table S1: Office for National Statistics (ONS) Questions. Table S2: The Short Warwick-Edinburgh Mental Well-being Scale (SWEMWBS). Table S3: Social Trust Question. Table S4: Relationship between season and the nine measures of subjective well-being. The results are from the chi-squared test, including $\mathrm{p}$ value, chi-test value, degree of freedom, and contingency assumption. WB measure ranges from $0-4$ and $1-4$.

Author Contributions: S.M. conceived the study idea and designed the framework. M.E. designed the data collection tools, collected the data, and conducted the statistical analysis. S.M. and M.E. wrote and revised the manuscript.

Funding: This research received no external funding.

Acknowledgments: This research was supported by the Ministry of Higher Education and Scientific Research-Libya through the Canadian Bureau for International Education, CBIE, and Denver Department of Public Health and Environment (DDPHE). The authors thank the study participants for their contribution to the study. We also thank the following non-profit organization for the feedback and the huge help during the recruiting process: Groundwork Denver, Triple Creek in Greeley, Growhaus in Elyria-Swansea, and Taking Neighborhood Health to Heart-Denver. Special thanks go to Josue Hernandez and Ethan Zerpablanco for the Spanish translation of the Smartphone Application and the survey. We appreciate the assistance from Eduardo Soderberg in recruiting study subjects.

Conflicts of Interest: The authors declare no conflict of interest.

\section{References}

1. Denver Department of Public Health and Environment. Environment, Final Report: The Denver Urban Air Toxics Assessment Methodology Results and Risks; Denver Department of Public Health and Environment: Denver, CO, USA, 2006.

2. Denver Department of Public Health and Environment. Environment, the Globeville and Elyria Swansea Health Impact Assessment Report; Denver Department of Public Health and Environment: Denver, CO, USA, 2014.

3. Morgan, B.; Hansgen, R.; Hawthorne, W.; Miller, S.L. Industrial odor sources and air pollutant concentrations in Globeville, a Denver, Colorado neighborhood. J. Air Waste Manag. Assoc. 2015, 65, 1127-1140. [CrossRef] [PubMed]

4. Blanes-Vidal, V.; Suh, H.; Nadimi, E.; Løfstrøm, P.; Ellermann, T.; Andersen, H.V.; Schwartz, J. Residential exposure to outdoor air pollution from livestock operations and perceived annoyance among citizens. Environ. Int. 2012, 40, 44-50. [CrossRef] [PubMed]

5. Sadick, A.-M.; Issa, M.H. Occupants' indoor environmental quality satisfaction factors as measures of school teachers' well-being. Build. Environ. 2017, 119, 99-109. [CrossRef]

6. Sucker, K.; Both, R.; Bischoff, M.; Guski, R.; Krämer, U.; Winneke, G. Odor frequency and odor annoyance Part II: Dose-response associations and their modiWcation by hedonic tone. Int. Arch. Occup. Envirn. Health 2008, 81, 683-694. [CrossRef] [PubMed]

7. Zarra, T.; Naddeo, V.; Belgiorno, V.; Reiser, M.; Kranert, M. Odour monitoring of small wastewater treatment plant located in sensitive environment. Water Sci. Technol. 2008, 58, 89-94. [CrossRef] [PubMed]

8. Shusterman, D.; Lipscomb, J.; Neutra, R.; Satin, K. Symptom prevalence and odor-worry interaction near hazardous waste sites. Environ. Health Perspcitives 1991, 94, 25-30. [CrossRef]

9. Meggs, W.J. Neurogenic inflammation and sensitivity to environmental chemicals. Environ. Health Perspectives 1993, 101, 234-238. [CrossRef] 
10. Russell, M.; Dark, K.A.; Cummins, R.W.; Ellman, G.; Callaway, E.; Peeke, H.V. Learned Histamine Release. Seience 1984, 225, 733-734. [CrossRef]

11. Shareefdeen, Z.; Herner, B.; Webb, D.; Wilson, S. Biofiltration eliminates nuisance chemical odors from industiral air streams. J. Ind. Microbiol. Biotechnol. 2003, 30, 168-174. [CrossRef] [PubMed]

12. Dincer, F.; Muezzinoglu, A. Chemical characterization of odors due to some industrial and urban facilities in Izmir, Turkey. Atmos. Environ. 2006, 40, 4210-4219. [CrossRef]

13. Noguchi, M.; Mizukoshi, A.; Yanagisawa, Y.; Yamasaki, A. Measurements of Volatile Organic Compounds in a Newly Built Daycare Center. Int. J. Environ. Res. Public Health 2016, 13, 736. [CrossRef] [PubMed]

14. Bereznicki, S.D.; Heber, A.J.; Jacko, R.B.; Akdeniz, N.; Jacobson, L.D.; Hetchler, B.P.; Heathcote, K.Y.; Hoff, S.J.; Kosiel, J.A.; Cai, L.; et al. Odor and chemical emissions from dairy and swine facilities: Part 1-Project Overview and Collection Methods. In Proceedings of the International Symposium on Air Quality and Manure Management for Agriculture, Dallas, TX, USA, 13-16 September 2010.

15. Brohus, K.H.; Nielsen, H.N.; Clausen, P.V.; Fanger, P.O. Perceived Air Quality in a Displacement Ventilated Room. In Indoor Air 96 7th Internatinal Conference on Indoor Air Quality and Climate, Nagoya, Japan, 21-26 July 1996; Danish National: Nagoya, Japan, 1996.

16. Fanger, P.O. Introduction of the olf and the decipol units to quantify air pollution perceived by humans indoors and outdoors. Energy Build. 1988, 12, 1-6. [CrossRef]

17. Kosonen, R.; Tan, F. The effect of perceived indoor air quality on productivity loss. Energy Build. 2004, 36, 981-986. [CrossRef]

18. Wargocki, P.; Wyon, D.P.; Sundell, J.; Clausen, G.; Fanger, P.O. The effects of Outdoor Air Supply Rate in an Office on Perceived Air Quality, Sick Building Syndrome (SBS) Symptoms and Productivity. Indoor Air 2000, 10, 222-236. [CrossRef] [PubMed]

19. Wargocki, P. Sensory pollution sources in buildings. Indoor Air 2004, 14, 82-91. [CrossRef] [PubMed]

20. Frontczak, M.; Schiavon, S.; Goins, J.; Arens, E.; Zhang, H.; Wargocki, P. Quantitative relationships between occupant satisfaction and satisfaction aspects of indoor environmental quality and building design. Indoor Air 2012, 22, 119-131. [CrossRef] [PubMed]

21. Qian, H.; Zheng, X.; Zhang, M.; Weschler, L.; Sundell, J. Association between parents' perceived air quality in homes and health among children in Nanjing, China. PLoS ONE 2016, 11, e0155742. [CrossRef] [PubMed]

22. Horstman, S.W.; Wromble, R.F.; Heller, A.N. Identification of community odor problems by use of an observer corps. J. Air Pollut. Control Assoc. 1965, 15, 261-264. [CrossRef] [PubMed]

23. Hellman, T.M.; Small, F.H. Characterization of the odor properties of 101 petrochemical using sensory methods. J. Air Pollut. Controal Assoc. 2012, 24, 979-982. [CrossRef]

24. Sucker, K.; Both, R.; Bischoff, M.; Guski, R.; Winneke, G. Odor fequency and odor annoyance. Part I: Assessment of frequency, intensity and hedonic tone of environmental odors in the field. Int. Arch. Occup. Environ. Health 2008, 81, 671-682. [CrossRef] [PubMed]

25. Steinheider, B. Environmental odours and somatic complaints. Zent. Hyg. Umweltmed. 1998, 202, 101-119.

26. Luginaah, I.N.; Martin Taylor, S.; Elliott, S.J.; Eyles, J.D. Community reappraisal of the perceived health effects of a petroleum refinery. Soc. Sci. Med. 2002, 55, 47-61. [CrossRef]

27. Pedersen, E. City Dweller Responses to Multiple Stressors Intruding into. Int. J. Environ. Res. Public Health 2015, 12, 3246-3263. [CrossRef] [PubMed]

28. Latif, E. Crisis, unemployment and psychological wellbeing in Canada. J. Policy Model. 2010, 32, 520-530. [CrossRef]

29. Dolan, P.; Peasgood, T.; White, M. Do we really know what makes us happy? A review of the economic literature on the factors associated with subjective well-being. J. Econ. Psychol. 2008, 29, 94-122. [CrossRef]

30. Clark, A.E.; Oswald, A.J. Unhappiness and unemployment. Econ. J. 1994, 104, 648-659. [CrossRef]

31. Clark, A.E.; Oswald, A.J. A simple statistical method for measuring how life events affect happiness. Int. J. Epidemiol. 2002, 31, 1139-1144. [CrossRef] [PubMed]

32. Flatau, P.; Galea, J.; Petridis, R. Mental Health and Wellbeing and Unemployment. Aust. Econ. Rev. 2000, 33, 161-181. [CrossRef]

33. Helliwell, J.F. How's life? Combining individual and natinal variables to explain subjective well-being. Econ. Model. 2003, 20, 331-360. [CrossRef]

34. Kahneman, D.; Deaton, A. High income improves evaluation of life but not emotional well-being. Proc. Natl. Acad. Sci. USA 2010, 107, 16489-16493. [CrossRef] [PubMed] 
35. Steptoe, A.; Deaton, A.; Stone, A.A. Subjective wellbeing, health and ageing. Lancet 2015, 385, 640-648. [CrossRef]

36. Stone, A.A.; Schwartz, J.E.; Broderick, J.E.; Deaton, A. A snapshot of the age distribution of psychological well-being in the United States. Proc. Natl. Acad. Sci. USA 2010, 107, 9985-9990. [CrossRef] [PubMed]

37. Hicks, S.; Tinkler, L.; Allin, P. Measuring Subjective Well-Being and its Potential Role in Policy: Perspectives from the UK Office for National Statistics. Soc. Ind. Res. 2013, 114, 73-86. [CrossRef]

38. Diener, E.; Pressman, S.D.; Hunter, J.; Delgadillo-Chase, D. If, Why, and When Subjective Well-Being Influences Health, and Future Needed Research. Appl. Psychol. Health Well Being 2017, 9, 133-167. [CrossRef] [PubMed]

39. Petra, K.J.; Piver, W.T.; Ye, F.; Elixhauser, A.; Olsen, L.M.; Portier, C.J. Temperature, Air Pollution, and Hospitalization for Cardiovascular Diseases among Elderly People in Denver. Environ. Health Perspectives 2003, 111, 1312-1317.

40. Steinheider, B.; Winneke, G.; Schlipkoter, H.W. Somatic and psychological effects of malodours: A case study from a mushroom fertilizer production plant. Staub Reinhalt. Luft 1993, 53, 425-431.

41. Zuri, I.; Gottreich, A.; Terkel, J. Social Stress in Neighboring and Encountering Blind Mole-Rats (Spalax ehrenbergi). Physiol. Behav. 1998, 64, 611-620. [CrossRef]

42. Dimsdale, J.E. Psychological Stress and Cardiovascular Disease. J. Am. Coll. Cardiol. 2008, 51, $1237-1246$. [CrossRef] [PubMed]

43. Cohen, S.; Janicki-Deverts, D.; Miller, G.E. Psychological Stress and Disease. J. Am. Med. Assoc. 2007, 298, 1685-1687. [CrossRef] [PubMed]

44. Schiffman, S.S.; Sattely-Miller, E.; Suggs, M.S.; Graham, B.G. The Effect of Environmental Odors Emanating From Commercial Swine Operations on the Mood of Nearby Residents. Br. Res. Bull. 1995, 37, 369-375. [CrossRef]

45. Nordin, S.; Aldrin, L.; Claeson, A.S.; Andersson, L. Effects of Negative Affectivity and Odor Valence on Chemosensory and Symptom Perception and Perceived Ability to Focus on a Cognitive Task. Perception 2017, 46, 431-446. [CrossRef] [PubMed]

46. Data USA. 2014. Available online: www.datausa.io (accessed on 11 November 2017).

47. Statistical Atlas. 2015. Available online: https://statisticalatlas.com (accessed on 5 April 2018).

48. Colorado Department of Local Affairs. 2018. Available online: https://demography.dola.colorado.gov/ census-acs/2010-census-data/ (accessed on 5 April 2018).

49. New Economics Foundation (NEF). Introducing the Five Headline Indicators of National Success; NEF: London, UK, 2015.

50. Anderson, M.J.; Daly, E.P.; Miller, S.L.; Milford, J.B. Source apportionment of exposures to volatile organic compounds: IApplication of receptor models to TEAM study data, I. Atmos. Environ. 2002, 36, 3643-3658. [CrossRef]

51. Tabachnick, B.G.; Fidell, L.S. Using Multivariate Statistics; Allyn \& Bacon, Inc.: Needham Heights, MA, USA, 2006.

52. Henson, R.K.; Roberts, K.J. Use of Exploratory Factor Analysis in Published Research. Educ. Psychol. Meas. 2006, 66, 393-416. [CrossRef]

53. Pett, M.A.; Lackey, N.R.; Sullivan, J.J. Making Sense of Factor Analysis: The Use of Factor Analysis for Instrument Development in Health Care Research; Sage Publications Inc.: Thousand Oaks, CA, USA, 2003.

54. Cerny, B.A.; Kaiser, H.F. A Study Of A Measure of Sampling Adequacy For Factor-Analytic Correlation Matrices. Multivar. Behav. Res. 1977, 12, 43-47. [CrossRef] [PubMed]

55. Snedecor, G.W.; Cochran, W.G. Statistica Methods; Iowa State University Press: Iowa City, IA, USA, 1989.

56. Hair, J.F.; Anderson, R.E.; Tatham, R.L.; Black, W.C. Multivariate Data Analysis, 4th ed.; Prentice-Hall Inc.: Upper Saddle River, NJ, USA, 1995.

57. Lipsitz, S.R.; Fitzmaurice, G.M.; Molenberghs, G. Goodness-of-fit Tests for Ordinal Response Regression Models. J. R. Stat. Soc. 1996, 45, 175-190. [CrossRef]

58. Fagerland, M.W.; Hosmer, D.W. A goodness-of-fit test for the proportional odds regression model. Stat. Med. 2013, 32, 2235-2249. [CrossRef] [PubMed]

59. Fagerland, M.W.; Hosmer, D.W. Tests for goodness of fit in ordinal logistic regression models. J. Stat. Comput. Simul. 2016, 86, 3398-3418. [CrossRef] 
60. Whitehead, J. Sample size calculations for ordered categorical data. Stat. Med. 1993, 12, 2257-2271. [CrossRef] [PubMed]

61. Campbell, M.J.; Julious, S.A.; Altman, D.G. Estimating sample sizes for binary, ordered categorical, and continuous outcomes in two group comparisons. BMJ 1995, 311, 1145-1148. [CrossRef] [PubMed]

62. Walters, S.J. Samplesize and power estimation for studies with health related quality of life outcomes: A comparison of four methods using the SF-36. Health Qual. Life Outcomes 2004, 2, 26-41. [CrossRef] [PubMed]

63. Van der Ploeg, T.; Austin, P.C.; Steyerberg, E.W. Modern modelling techniques are data hungry: A simulation study for predicting dichotomous endpoints. BMC Med. Res. Methodol. 2014, 14, 137. [CrossRef] [PubMed]

64. Altman, D.G.; Royston, P. The cost of dichotomising continuous variables. Br. Med. J. 2006, 332, 1080. [CrossRef] [PubMed]

65. Theodossiou, I. The effect of low-pay and unemployment on psychological well-being: A logistic regression approach. J. Health Econ. 1998, 17, 85-104. [CrossRef]

66. Bardasi, E.; Francesconi, M. The impact of atypical employment on individual wellbeing: Evidence from a panel of British workers. Soc. Sci. Med. 2004, 58, 1671-1688. [CrossRef]

67. Blanchflower, D.G.; Oswald, A.J. Well-being over time in Britain and the USA. J. Public Econ. 2004, 88, 1359-1386. [CrossRef]

68. Creed, A.P.; Watson, T. Age, Gender, Psychological Wellbeing and the Impact of Losing the Latent and Manifest Benefits of Employment in Unemployed People. Aust. J. Psychol. 2003, 55, 95-103. [CrossRef]

69. Chen, L.; Li, W.; He, J.; Wu, L.; Yan, Z.; Tang, W. Mental health, duration of unemployment, and coping strategy: A cross-sectional study of unemployed migrant workers in eastern china during the economic crisis. BMC Public Health 2012, 12, 597. [CrossRef] [PubMed]

70. Louis, V.V.; Zhao, S. Effects of Family Structure, Family SES, and Adulthood Experiences on Life Satisfaction. J. Fam. Issues 2002, 23, 986-1005. [CrossRef]

71. Maccoby, E.E.; Jacklin, C.N. The Psychology of Sex Differences; Stanford University Press: Stanford, CA, USA, 1974.

72. Kohr, R.L.; Coldiron, J.R.; Skiffington, W.E.; Masters, R.J.; Blust, R.S. The Influence of Race, Class, and Gender on Self-Esteem for Fifth Eighth, and Eleventh Grade Students in Pennsylvania Schools. J. Negro Educ. 1988, 57, 467-481. [CrossRef]

73. Haring, M.J.; Stock, W.A.; Okun, M.A. A research synthesis of gender and social class as correlates of subjective well-being. Human Relat. 1984, 37, 645-657. [CrossRef]

74. Wu, A.C.; Donnelly-McLay, D.; Weisskopf, M.G.; McNeely, E.; Betancourtr, T.S.; Allen, J.G. Airplane pilot mental health and suicidal thoughts: A cross-sectional descriptive study via anonymous web-based survey. Environ. Health 2016, 15, 121. [CrossRef] [PubMed]

75. Clark, A.; Oswald, A.; Warr, P. Is job satisfaction U-shaped in age? J. Occup. Organ. Psychol. 1996, 69, 57-81. [CrossRef]

76. Blanchflower, D.G.; Oswald, A.J. Is well-being U-shaped over the life cycle? Soc. Sci. Med. 2008, 66, 1733-1749. [CrossRef] [PubMed]

77. Wing, S.; Wolf, S. Intensive Livestock Operations, Health, and Quality of Life among Eastern North Carolina Residents. Environ. Health Perspectives 2000, 108, 233-238. [CrossRef]

78. Skok, A.; Harvey, D.; Reddihough, D. Perceived stress, perceived social support, and wellbeing among mothers of school-aged children with cerebral palsy. J. Intellect. Dev. Dis. 2006, 31, 53-57. [CrossRef] [PubMed]

79. Sheffield, D.; Dobbie, D.; Carroll, D. Stress, social support, and psychological and physical well-being insecondary school teachers. Work Stress 1994, 8, 235-243. [CrossRef]

80. Tilaki, K.H. Methodological issues of confounding in analytical epidemiologic studies. Casp. J. Intern. Med. 2012, 3, 488-495.

81. Skelly, A.C.; Dettori, J.R.; Brodt, E.D. Assessing bias: The importance of considering confounding. Evid. Based Spine Care J. 2012, 3, 9-12. [CrossRef] [PubMed]

82. Evans, J.L.; Hahn, J.A.; Page-Shafer, K.; Lum, P.J.; Stein, E.S.; Davidson, P.J.; Moss, A.R. Gender Differences in Sexual and Injection Risk Behavior Among Active Young Injection Drug Users in San Francisco (the UFO Study). J. Urban Health 2003, 80, 137-146. [CrossRef] [PubMed]

83. Zhang, L.F. Do age and gender make a difference in the relationship between intellectual styles and abilities? Eur. J. Psychol. Educ. 2010, 25, 87-103. [CrossRef] 
84. Silva, I. Cancer Epidemiology: Principles and Methods; IARC Press: Lyon, France, 1999.

85. Rubin, D.B.; Stern, H.S.; Vehovar, V. Handling "Don't know" survey responses: The case of the slovenian plebiscite. J. Am. Stat. Assoc. 1995, 90, 822-828.

86. Manisera, M.; Zuccolotto, P. Modeling “don't know" responses in rating scales. Pattern Recognit. Lett. 2014, 45, 226-234. [CrossRef] 